\title{
Pyrazolyl-Tetrazoles and Imidazolyl-Pyrazoles as Potential Anticoagulants and their Integrated Multiplex Analysis Virtual Screening
}

\author{
André L. P. G. Lourenço, ${ }^{a, b}$ Percilene F. Vegi, Jéssica V. Faria, ${ }^{c}$ Gustavo S. P. Pinto, ${ }^{c}$ \\ Maurício S. dos Santos, ${ }^{\oplus * d}{ }^{*}$ Plínio C. Sathler, ${ }^{e}$ Max S. Saito, ${ }^{a}$ Marcos Santana, ${ }^{f}$ \\ Tatiana P. P. Dutra, ${ }^{g}$ Carlos R. Rodrigues, ${ }^{b}$ Robson Q. Monteiro, ${ }^{g}$ \\ Alice M. R. Bernardino ${ }^{c}$ and Helena C. Castro $^{a_{1} f}$
}

aPrograma de Pós-Graduação em Patologia, Hospital Universitário Antônio Pedro, Universidade Federal Fluminense, 24033-900 Niterói-RJ, Brazil

${ }^{b}$ Laboratório de Modelagem Molecular e QSAR (ModMolQSAR), Faculdade de Farmácia, Universidade Federal do Rio de Janeiro, 21941-170 Rio de Janeiro-RJ, Brazil

'Programa de Pós-Graduação em Química, Laboratório de Síntese de Heterociclos (LASINTHET), Instituto de Química, Universidade Federal Fluminense, 24020-150 Niterói-RJ, Brazil

${ }^{d}$ Programa de Pós-Graduação Multicêntrico em Química de Minas Gerais,

Laboratório de Síntese Orgânica (LABSINTO), Instituto de Física e Química, Universidade Federal de Itajubá, 37500-903 Itajubá-MG, Brazil

${ }^{e}$ Laboratório de Tecnologia Farmacêutica, Instituto de Biologia, Universidade Federal do Rio de Janeiro, 21941-902 Rio de Janeiro-RJ, Brazil

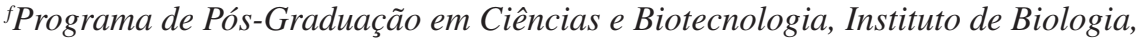
Universidade Federal Fluminense, 24020-140 Niterói-RJ, Brazil

${ }^{8}$ Laboratório de Trombose e Câncer, Instituto de Bioquímica Médica Leopoldo de Meis, Universidade Federal do Rio de Janeiro, 21941-902 Rio de Janeiro-RJ, Brazil

This article reports a novel virtual screening algorithm seeking the rational identification of novel lead anticoagulants. Seven 5-(3-methyl-1-aryl-1H-pyrazol-4-yl)-1H-tetrazoles and seven novel 1-aryl-4-(4,5-dihydro- $1 H$-imidazol-2-yl)-3-methyl-1 $H$-pyrazoles were obtained in three steps starting from arylhydrazine hydrochlorides as raw materials in good yields: $50-72 \%$ and $50-85 \%$, respectively. All compounds were submitted to an in silico target-base pipeline named integrated multiplex analysis virtual screening (IMA-VS), which comprises the evaluation of their (i) fitting physicochemical properties to the chemical environment of the target enzyme; (ii) active-site homing electrostatic potential to the target enzyme; (iii) structural fitting to the target active site through molecular docking; and (iv) overall absorption, distribution, metabolism, excretion and toxicity (ADMET) profile. After the virtual selection of potential anticoagulant hits, all molecules were synthesized and candidates were evaluated in vitro for their anticoagulant and hemolytic profile. The most promising candidate pointed out by IMA-VS was compound 1-(3',4'-dichlorophenyl)-4-(4,5-dihydro-1H-imidazol-2-yl)-3-methyl-1 $H$-pyrazole that shown to display factor $\mathrm{Xa}(\mathrm{FXa})$-specific inhibitory activity in vitro, acting as an uncompetitive inhibitor with an inhibition constant $(\mathrm{Ki})=61.16 \pm 12.96 \mu \mathrm{M}$, in addition to the lowest hemolytic activity of the series. Further experiments revealed the antithrombotic activity of this compound in an in vivo model of arterial thrombosis induced by $\mathrm{FeCl}_{3}$.

Keywords: anticoagulant, pyrazole, imidazolyl, tetrazole, molecular docking

*e-mail: mauriciosantos@unifei.edu.br 


\section{Introduction}

The development of small molecules that interact with specific biological targets and disturb their cellular function has emerged as a crucial aspect of modern medicinal chemistry and biochemistry over the last few decades. ${ }^{1}$ The drug discovery and development pathway from a novel drug target to a Food and Drug Administration (FDA) approved drug and to the marketing of a novel molecular entity is long and expensive, which prompts new pharmaceutical companies and laboratories to benefit from the usage of computational methods. ${ }^{2,3}$

Computational methods now play an integral role in understanding intermolecular interactions and although algorithms are based on approximations and assumptions, molecular modeling has become the leading tool in modern drug discovery. ${ }^{4,5}$ The ability of specialized virtual screening algorithms to filter molecular libraries into a manageable number of compounds for biological assays is the driving force for finding novel ligands. 5,6 When the structural information of the target protein is unknown, the screening file is made as diverse as possible and ligand-based approaches are employed to scan the compound library. ${ }^{7,8}$ On the other hand, when structural information on the target or target family is available, the strategy switches to a target-based approach, such as molecular docking, in an attempt to predominantly screen compounds that can be expected to modulate the target

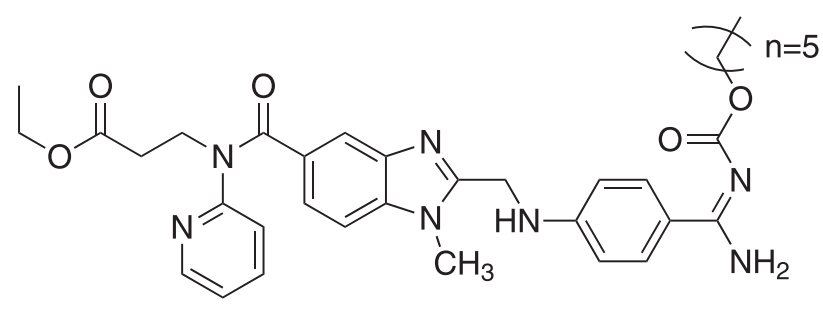

Dabigatran etexilate

Pradaxa®, 2010<smiles>COc1ccc(-n2nc(C(N)=O)c3c2C(=O)N(c2ccc(N4CCCCC4=O)cc2)CC3)cc1</smiles>

Apixaban

Eliquis®, 2012 and improve them using fragment-based optimization. ${ }^{7-9}$

Although several lead molecules have been discovered through the usage of in silico libraries in a structure-based approach, ${ }^{10}$ one major challenge for this field is to develop methods able to generate drug-like leads without losing too much ligand efficiency and favorable physical properties. ${ }^{11}$ Molecular approaches that combine knowledge of known ligands properties with the understanding of structural particularities of the target may lead to the development of a target-focused compound library, from which fewer compounds need to be screened in order to obtain successful hit compounds. ${ }^{12}$

The recently introduced new oral anticoagulants that selectively target thrombin (dabigatran etexilate) or factor $\mathrm{Xa}$ (FXa; rivaroxaban, apixaban) (Figure 1) are attractive candidates for both venous and arterial thrombosis. ${ }^{13,14}$ However, despite these motivating factors, these novel agents face significant challenges from intracranial and gastrointestinal bleeding, dyspepsia, liver and renal dysfunction due to a difficult pharmacokinetic profile, lack of reversal agents, ${ }^{15}$ and even mild relationship with the development of acute coronary syndrome events after usage. ${ }^{14}$

In medicinal chemistry, many compounds containing pyrazole moiety have exhibited biological activity, ${ }^{16}$ such as apixaban (Figure 1), ${ }^{17}$ which has been approved for the treatment of venous thromboembolism, ${ }^{18}$ revealing the potential of pyrazole derivatives as promising for the inhibition of coagulation factors such as thrombin<smiles>O=C(NC[C@H]1CN(c2ccc(N3CCOCC3=O)cc2)C(=O)O1)c1ccc(Cl)s1</smiles>

Rivaroxaban Xarelto®, 2011<smiles>C[C@@H]1CNc2c(cccc2S(=O)(=O)N[C@@H](CCCNC(=N)N)C(=O)N2CC[C@@H](C)C[C@H]2C(=O)O)C1</smiles>

Argatroban Acova $\Re_{2} 2000$

Figure 1. Chemical structures of anticoagulant drugs and their respective years of approval by the FDA. 
or FXa. Many successful anticoagulants, such as the direct thrombin inhibitors argatroban (Figure 1), chosen as treatment of patients with heparin induced thrombocytopenia, ${ }^{19}$ and dabigatran etexilate (Figure 1), used for multiple thromboembolic disease indications, ${ }^{20}$ are highly water-soluble, poorly absorbable and direct thrombin inhibitors. ${ }^{21,22}$ Such features are mainly due to the presence of charged groups able to make the molecular structure highly hydrated and water-soluble. ${ }^{23}$ The importance of such characteristics prompted us to build our library based upon molecules with predictable water solubility profile.

In this work, we designed a novel integrated multiplex analysis virtual screening (IMA-VS) algorithm for the identification of new lead anticoagulants. The algorithm is portioned into four communicating phases of which a targetbased library is prone to evaluation: (i) fitting physicochemical properties; (ii) stereoelectronic properties; (iii) structural complementarity to target protein; and (iv) low toxicological risk (Figure 2). To test the power of the algorithm, novel 4,5-dihydro- $1 \mathrm{H}$-imidazole substituted molecules were synthesized and were shown to address important requirements for optimal anticoagulant activity, such as water solubility ${ }^{24}$ favorable electrostatic complementarity to the electron-rich active site of the coagulation factors and structural similarities to the target preferable substrate paired with low toxicological risk and high lead likeness. ${ }^{25,26}$

In this work, we built a library from compounds bearing a pyrazole moiety with a $1 \mathrm{H}$-tetrazole ring, the 5-(3-methyl1-aryl-1H-pyrazol-4-yl)- $1 H$-tetrazoles (1a-g), previously synthesized by our research group as antileishmanial agents (Figure 3). ${ }^{27}$

Based on the potential anticoagulant activity related to pyrazole and imidazoline systems, in this work we developed a synthetic route to achieve the novel 1-aryl4-(4,5-dihydro-1 $H$-imidazol-2-yl)-3-methyl- $1 H$-pyrazoles (5a-g) (Scheme 1). This new series was added to the targetbased library and further evaluated along their tetrazole counterparts.

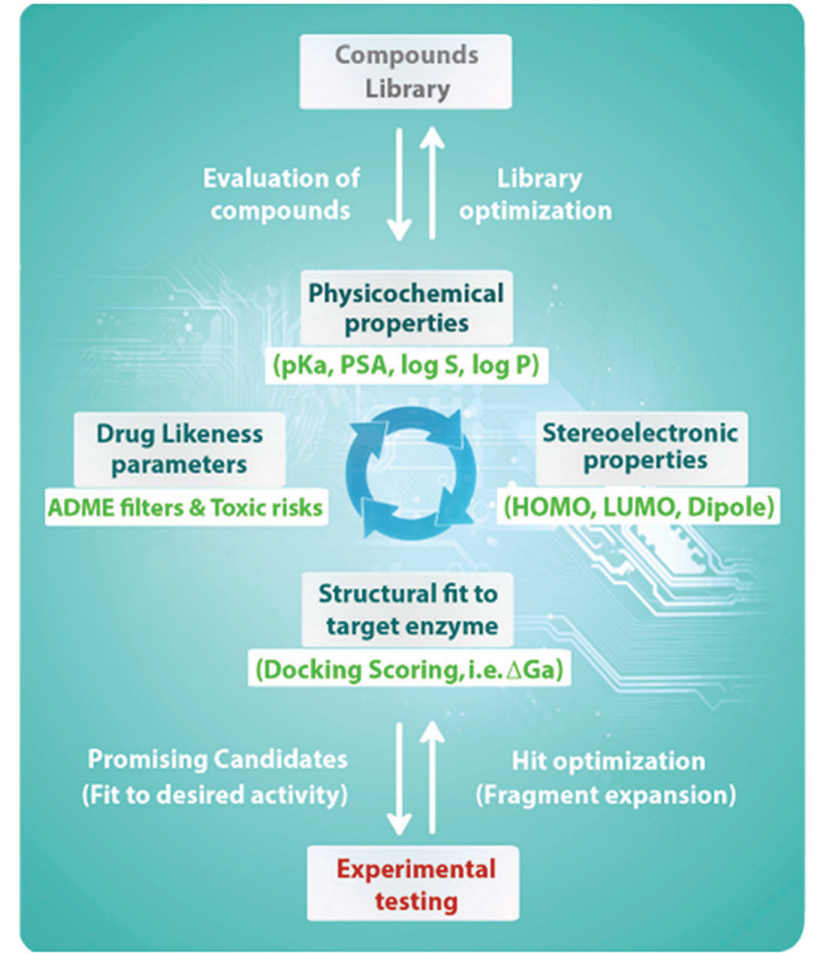

Figure 2. Visual pipeline for the IMA-VS algorithm. A target-based compound library is assembled and optimized as molecules undergo computation evaluation over four sequential and eliminatory phases.

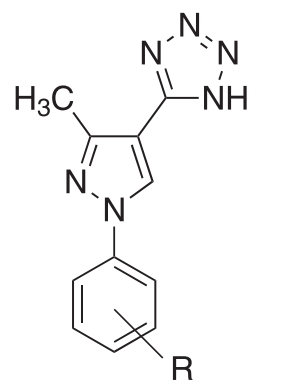

(1a-g)
Figure 3. Pyrazolyl- $1 H$-tetrazole derivatives (1a-g).

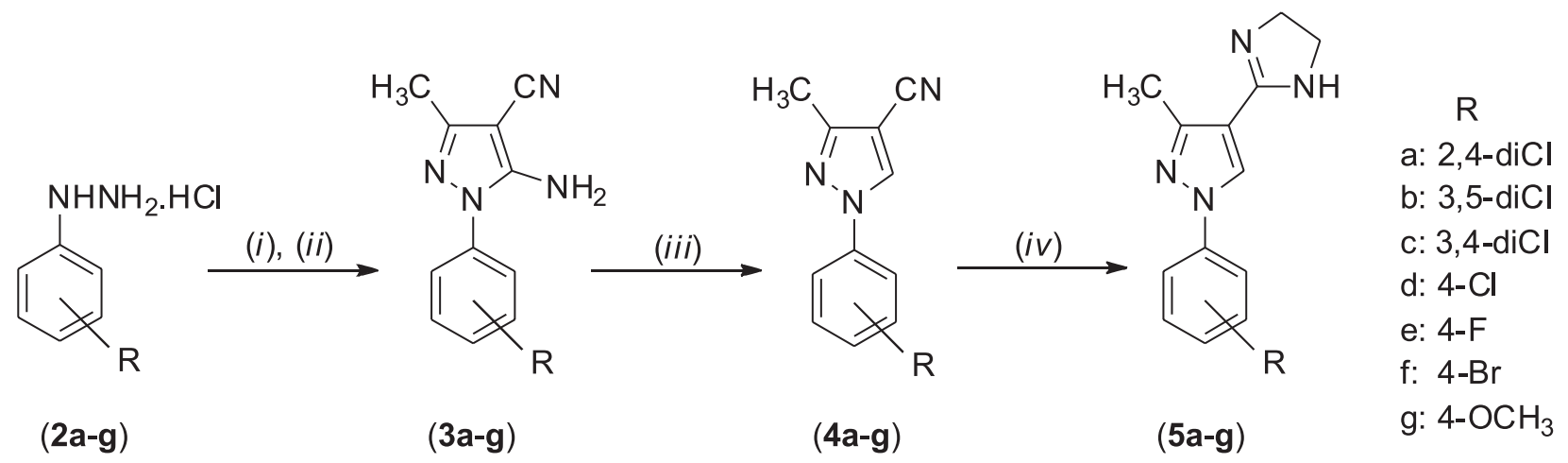

Scheme 1. Synthetic route to obtain 1-aryl-4-(4,5-dihydro-1H-imidazol-2-yl)-3-methyl-1H-pyrazoles (5a-g). Reagents and conditions: (i) sodium acetate, ethanol, $30 \mathrm{~min}$; (ii) (ethoxyethylidene)malononitrile, $2 \mathrm{~h}$, reflux; (iii) t-butylnitrite, THF, $2 \mathrm{~h}$, reflux; and (iv) ethylenediamine, $\mathrm{CS}_{2}, 17 \mathrm{~h}, 110{ }^{\circ} \mathrm{C}$. 


\section{Results and Discussion}

\section{Chemistry}

The targets (5a-g) were obtained in three steps (Scheme 1). In the first step, arylhydrazine hydrochlorides (2a-g) were reacted with sodium acetate, (ethoxyethylidene) malononitrile, and ethanol as solvent, to generate 5-amino1-aryl-3-methyl- $1 \mathrm{H}$-pyrazole-4-carbonitriles $(\mathbf{3 a - g}){ }^{28}$ These compounds were reacted with $t$-butylnitrite and tetrahydrofuran (THF) to give the key intermediates 1-aryl-3-methyl- $1 \mathrm{H}$-pyrazole-4-carbonitriles $(\mathbf{4 a - g}){ }^{28}$ Finally, the targets 1 -aryl-4-(4,5-dihydro- $1 \mathrm{H}$-imidazol2-yl)-3-methyl-1 $H$-pyrazoles (5a-g) were obtained by the reaction involving the key intermediates $(\mathbf{4 a -} \mathbf{- g})$, carbon disulfide and ethylenediamine.

\section{Physicochemical properties}

The first anticoagulant leads for direct FXa and thrombin competitive inhibition were highly basic amidines, able to mimic the substrate specificity to Asp189 at the S1 pocket of both serine (Ser) proteases. ${ }^{29,30}$ Crystallographic structures support electrostatic complementarity as the driving force towards high affinity complexes between the active site of thrombin and serpins. ${ }^{30}$ In a similar way, the protonation of the imidazoline ring orients the 4,5-dihydro- $1 H$-imidazolyl pyrazole compounds to interact with negative charges and possibly form stable complexes with coagulation factors.

Results from the physicochemical properties calculated using Marvin software 16.1.4.0 $0^{31}$ revealed that all designed imidazoline-substituted molecules have feasible cationic microspecies at blood $\mathrm{pH}$ (7.4) by direct protonation of the imidazoline moiety (Table 1). This expected protonation profile configures highly hydrated molecules with improved aqueous solubility for all molecules bearing a terminal 4,5-dihydro- $1 H$-imidazole ring, similar to hydrophilic molecules such as clonidine. ${ }^{32}$ This data is supported by previous reports from electron paramagnetic resonance that pointed out the protonation of 2-imidazoline group in imidazoline-based nitroxides, ${ }^{33}$ and also the development of dicationic compounds based on highly hydrophilic 2-imidazoline moieties similar to the rings found in the series described hereby. ${ }^{34}$ Similarly, all tetrazole-substituted molecules exhibit ionized microspecies at blood $\mathrm{pH}$ (7.4), presenting an overall negative charge, as expected for tetrazolium ions as carboxylic acid bioisosters (Table 1). The structures of pyrazolyl- $1 H$-tetrazole anionic derivatives (1a-g) and 4,5-dihydro-1 $H$-imidazolyl pyrazole cationic derivatives (5a-g) are shown in Figure 4.
Table 1. Predicted physicochemical properties of pyrazolyl- $1 H$-tetrazole anionic derivatives (1a-g) and 4,5-dihydro- $1 H$-imidazolyl pyrazole cationic derivatives (5a-g)

\begin{tabular}{lccccc}
\hline Compound & $\begin{array}{c}\text { Intrinsic } \\
\log \mathrm{S}\end{array}$ & $\mathrm{IM} / \%$ & $\begin{array}{c}\log \mathrm{S} \\
(\mathrm{pH} 7.4)\end{array}$ & PSA / $\AA^{2}$ & $\log \mathrm{P}$ \\
\hline 1a & -3.85 & 99.96 & -0.51 & 57.781 & 4.91 \\
$\mathbf{1 b}$ & -3.85 & 99.96 & -0.51 & 56.919 & 4.91 \\
$\mathbf{1 c}$ & -3.85 & 99.96 & -0.51 & 56.979 & 4.91 \\
$\mathbf{1 d}$ & -3.12 & 99.96 & 0.00 & 57.016 & 4.36 \\
$\mathbf{1 e}$ & -2.66 & 99.96 & 0.00 & 57.039 & 3.96 \\
$\mathbf{1 f}$ & -3.45 & 99.96 & -0.11 & 76.017 & 4.07 \\
$\mathbf{1 g}$ & -2.39 & 99.96 & 0.00 & 63.836 & 3.67 \\
$\mathbf{5 a}$ & -1.69 & 43.88 & -1.39 & 31.512 & 3.35 \\
$\mathbf{5 b}$ & -3.17 & 43.87 & -2.87 & 31.249 & 3.35 \\
$\mathbf{5 c}$ & -3.17 & 43.87 & -2.87 & 31.289 & 3.35 \\
$\mathbf{5 d}$ & -2.43 & 43.88 & -2.14 & 31.155 & 2.79 \\
$\mathbf{5 e}$ & -1.98 & 43.88 & -1.67 & 31.265 & 2.39 \\
$\mathbf{5 f}$ & -2.77 & 43.88 & -2.47 & 31.155 & 3.06 \\
$\mathbf{5 g}$ & -1.71 & 43.88 & -1.41 & 38.031 & 2.11 \\
\hline
\end{tabular}

$\log$ S: aqueous solubility; IM: ionized microspecies; PSA: polar surface area; $\log$ P: octanol-water partition coefficient.<smiles>Cc1nn(-c2ccccc2)cc1-c1nnn[nH]1</smiles>

(1a-g)<smiles>Cc1nn(-c2ccccc2)cc1C1=[NH+]CCN1</smiles>

$(5 a-g)$
$\mathrm{R}$

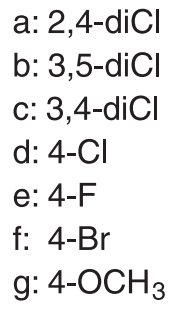
b: 3,5-diCl c: $3,4-\mathrm{diCl}$ d: $4-\mathrm{Cl}$ e: $4-\mathrm{F}$ f: $4-\mathrm{Br}$ g: $4-\mathrm{OCH}_{3}$
Figure 4. Anionic pyrazolyl-1 $H$-tetrazole (1a-g) and cationic 4,5-dihydro$1 H$-imidazolyl pyrazole (5a-g).

The compound library was filtered to remove problematic structures (such as covalent inhibitors and toxicophores) and using lead-like physicochemical parameters. The Free ADMET Filtering for Drugs 3 (FAF-Drugs 3$)^{35}$ web server did not classify any compound as problematic due to structural alerts or not satisfying the lead-like filter. Furthermore, using the "golden triangle" guideline (Figure 5) we observed that all compounds were in the lead likeness chemical space, characterized by low molecular weight and lipophilicity. Thus, we selected all compounds in the library for further screening.

\section{Stereoelectronic properties}

The evaluation of global stereoelectronic properties calculated using Spartan' $10^{37}$ revealed that all pyrazole derivatives shared the similar steric properties such as surface area and volume. Interestingly, each class of 


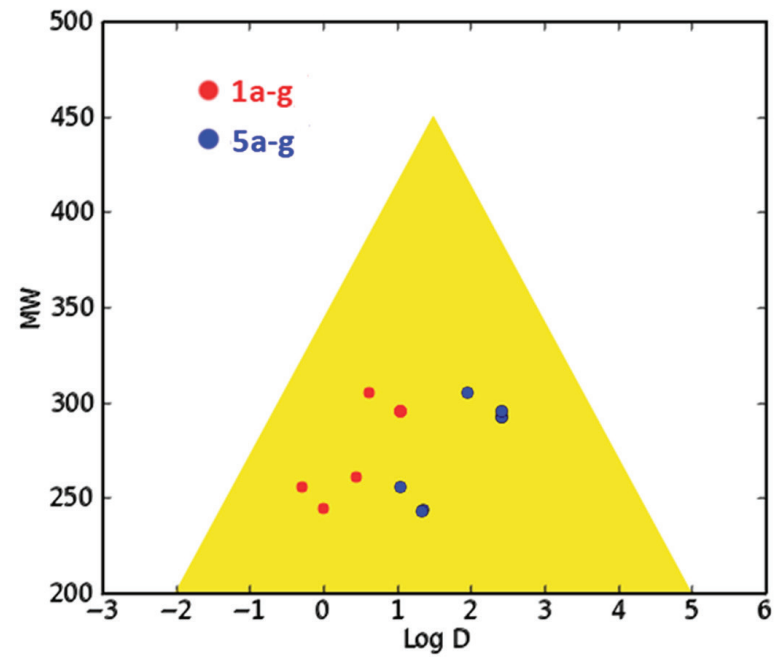

Figure 5. Both 1a-g and 5a-g series physicochemical properties displayed in the golden triangle lead likeness plot developed by Johnson et al. ${ }^{36}$ and available as an output of FAF-Drugs3 server.

pyrazole derivative presented a particular electronic profile revealing electronic disparity in between each series. Imidazoline substituted molecules presented similar highest occupied molecular orbital (HOMO) $\left(\mathrm{E}_{\text {номо }}=-10.57\right.$ to $-11.7 \mathrm{eV}$ ) and lowest unoccupied molecular orbital (LUMO) energy values $\left(\mathrm{E}_{\text {LUMo }}=-1.44\right.$ to $\left.-1.8 \mathrm{eV}\right)$ in comparison with known anticoagulant molecules such as benzamidine and the commercial drugs argatroban and dabigatran (Supplementary Information (SI) section, Table S1). This novel 5a-g series behaves as electrophilic moieties, a feature that is shared with commercial anticoagulants, especially those bearing non-cyclic amidines such as dabigatran (SI section, Table S1). Analysis of the electrostatic density maps reinforce the electronic similarity between the imidazoline-substituted compounds and known anticoagulant agents and reveals the unfitting electronic profile of tetrazole-substituted compounds to that of anticoagulant agents (Figure 6).

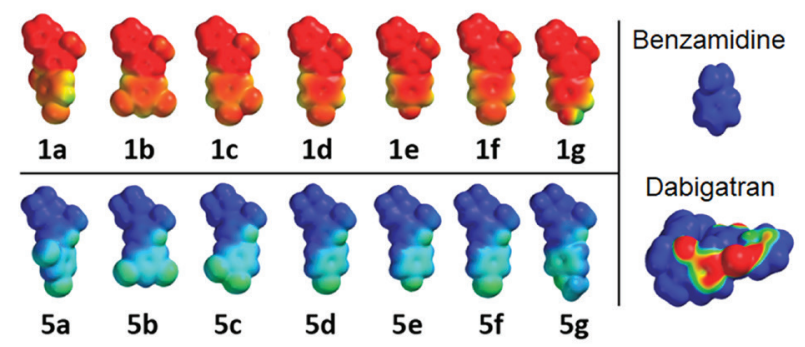

Figure 6. Electrostatic potential maps of the novel 4,5-dihydro$1 \mathrm{H}$-imidazolyl pyrazoles derivatives in comparison with commercial amidinic anticoagulants. Color range is defined from -250 to $350 \mathrm{eV}$. Blue and red indicate positive and negative charges distribution, respectively.

Trypsin-like serine proteases such as coagulation factors are known to have negative charged regions at their active site, especially due to the intrinsic selectivity of the S1 pocket for positively charged residues, such as lysine or arginine, as $\mathrm{P} 1$ groups of their substrate.$^{38}$ Preview data from literature points out that initial contacts between proteins and small ligand molecules occur as a result of feasible electrostatic interactions. ${ }^{39}$ Together, these data point to the anticoagulant potential of the 4,5-dihydro$1 \mathrm{H}$-imidazole series (5a-g) as feasible anticoagulant hits, able to interact with the active site of the coagulation factors, demonstrating the electronic complementarity that is often necessary for the protein-ligand binding. ${ }^{40}$

Literature reports a series of coagulation factor XIa inhibitors bearing a chlorophenyl-tetrazole as $\mathrm{P} 1$ group. ${ }^{41}$ Such feature is likely to be achieved in peptide-like molecules despite the unfavorable electrostatics of the tetrazole group. Contrary to small molecular fragments, the large molecular structure of peptide molecules is often enough to outweigh the electrostatic mismatch in P1 due to the gain in binding affinity obtained with well-matching $\mathrm{P} 2$ and $\mathrm{P} 3$ groups. ${ }^{42,43}$

\section{Molecular docking calculations}

The active sites of serine proteases generally consist of three binding pockets, S1, S2, and S3. The catalytic triad (Ser195, histidine (His)52, and aspartic acid (Asp)189) lies inside the $\mathrm{S} 2$ pocket. Classical serine protease inhibitors have a bulky moiety that enters S2 pocket to interact with Ser195 or tyrosine (Tyr)228, while leaving most of its surface exposed to the solvent. ${ }^{44}$ Given the improved electrostatic complementarity of $\mathbf{5 a}-\mathbf{g}$ series to both enzymes, in comparison with their 1a-g analogues, we evaluated the in silico binding modes of each molecule to human thrombin and FXa.

The complexes generated between our compound library with FXa revealed that, except for $\mathbf{1 b}$ and $\mathbf{5 b}$, ligands interacted with the macromolecule as predicted by inserting the substituted phenyl ring on S1 pocket, while the imidazole and tetrazole rings were exposed to the protein surface in contact with solvent. For compounds $\mathbf{1 b}$ and $\mathbf{5 b}$, the 3,5-dichloro substitution probably precluded their insertion on S1, a feature that usually accounts for a reduced or a lack of activity, since they might not interact with key residues on the active site (Figure 7). Our analysis of ligandthrombin complexes showed that 10 out of 14 compounds bound as predicted (Figure 7). Similarly to its complex with FXa, 1b bound on the surface of thrombin with the tetrazole ring pointing to the entrance of S1 pocket, while the 3,5-dichloro-phenyl ring was in direct contact with the solvent. On the other hand, $\mathbf{5 b}$ inserted its hydrophobic tail at $\mathrm{S} 1$ while exposing the protonated imidazole ring to 
the solvent. Surprisingly, derivatives $\mathbf{5 e}$ and $\mathbf{5 f}$ displayed a $180^{\circ}$ flip compared to their binding mode on FXa, with their imidazole ring inside the S1 pocket and the halogensubstituted tail pointing outward. It is possible that these binding mode shifts could translate to different activities on FXa and thrombin.

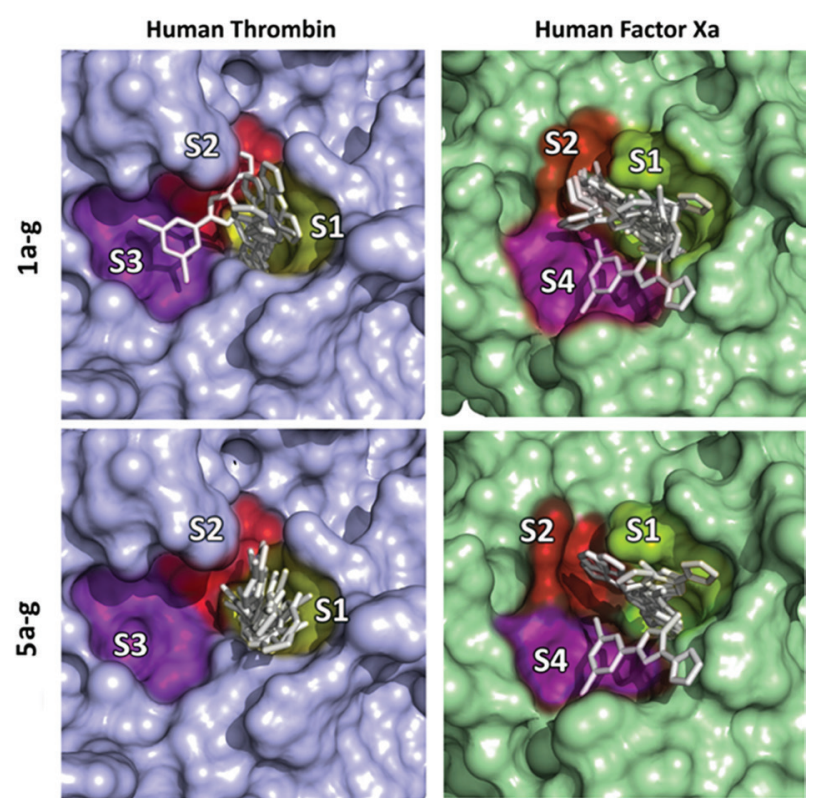

Figure 7. Molecular docking models of 1a-g and 5a-g series to the active site of both human thrombin (blue) and FXa (green). Substrate-specific pockets with known drug-interaction are shown for each enzyme as yellow (S1), red (S2) and pink (S3 in thrombin and S4 in FXa).

The docking results allowed us to select the most promising compounds based on binding mode analysis and electrostatic complementarity. Although both 1a-g and 5a-g series showed similar binding modes, their distinct electronic charges at physiological $\mathrm{pH}$ due to the presence of the tetrazole and imidazoline rings favors the electrostatic interaction and further accommodation of the 5a-g series to the active site of both enzymes. The binding energies resulting from AutoDock ${ }^{45}$ scoring functions point to compounds $\mathbf{5 b}$ and $\mathbf{5} \mathbf{c}$ as the most feasible for presenting relevant activity in a biological setting, particularly as FXa direct modulators (SI section, Table S2). For another chlorinated compound with lower binding energy score, 5d, a consistent docking pose was observed as a $1.90 \AA$ hydrogen bond established between the strong H-donor imidazoline ring and the carbonyl group from glycine (Gly)216 enables the dipole-dipole interaction between the 4-Cl phenyl ring to the centroid of the tyrosine ring from Tyr228. Such binding mode is widely accepted as a chloro- $\pi$ interaction (Figure $8 \mathrm{a}$ ), which is responsible for increased contact between FXa and effective ligands ${ }^{44}$ and is also observed for the best hit molecule $\mathbf{5 c}$, which poses in greater contact with the enzyme nucleophilic center at Ser195 (Figure 8b). The lower energy score observed for $\mathbf{5 b}$ at the lowest energy cluster derives from the establishment of two H-bonds with both Tyr99 and Gly216 (Figure 8c). This particular binding mode seems to occur in a similar frequency as the canonical insertion of the chlorinated phenyl ring to $S 1$ towards Tyr228 and as its analogue 5c, the binding configuration of $\mathbf{5 b}$ shields the enzyme nucleophile closer than observed for the third tightly bond compound, 5d (Figure 8d).

The similar binding modes observed for both 1a-g and 5a-g series demonstrate an example of how most structurebased drug design campaigns fail to consider unfavorable physicochemical properties into their scoring function, which often results in the election of false positives as hit molecules when physicochemical evaluation is not performed in tandem. ${ }^{46}$ Particularly, global electrostatics and ionized microspecies of potential ligands should be considered prior to any structural evaluation, while taking into account the specific $\mathrm{pH}$ in which the target enzyme is mostly found. ${ }^{47}$ By enriching our molecular library with ligand-based filters such as water availability, complementary electrostatics to the target enzyme and proper biodistribution, it is expected for the 5a-g series to display a predictive anticoagulant activity, as generally observed for several other ligands with respect to their target. ${ }^{48}$ Thus, we selected compounds 5a-g for experimental testing against human platelet-poor plasma to evaluate their anticoagulant properties.

Lead likeness parameters and in silico toxicology prediction

The evaluation of global drug likeness from all pyrazole derivatives revealed good oral bioavailability for the whole library members according to Lipinski and Lipinski-like filters applied (SI section, Table S3). Fragment-based parameters of drug likeness and drug score were evaluated using Osiris Property Explorer version $2.0^{49}$ as previously described. ${ }^{50}$ Analysis from Osiris Property Explorer software revealed that all 4,5-dihydro- $1 H$-imidazolyl pyrazoles derivatives (5a-g) presented a better fragmentbased drug likeness profile in comparison with the pyrazolyl$1 H$-tetrazole substituted analogs (Figure 9a), suggesting the improved pharmacophoric profile of 4,5-dihydro$1 H$-imidazolyl pyrazoles rings in comparison with analogs tetrazoles. The combined analysis of druglikeness, aqueous solubility (clog S), partition coefficient of $n$-octanol/water (clog P) and molecular weight values corroborates to such profile revealing better overall drug score values for the 5a-g series in comparison with the 1a-g series (Figure 9b). In fact, many imidazoline drugs are available today as 

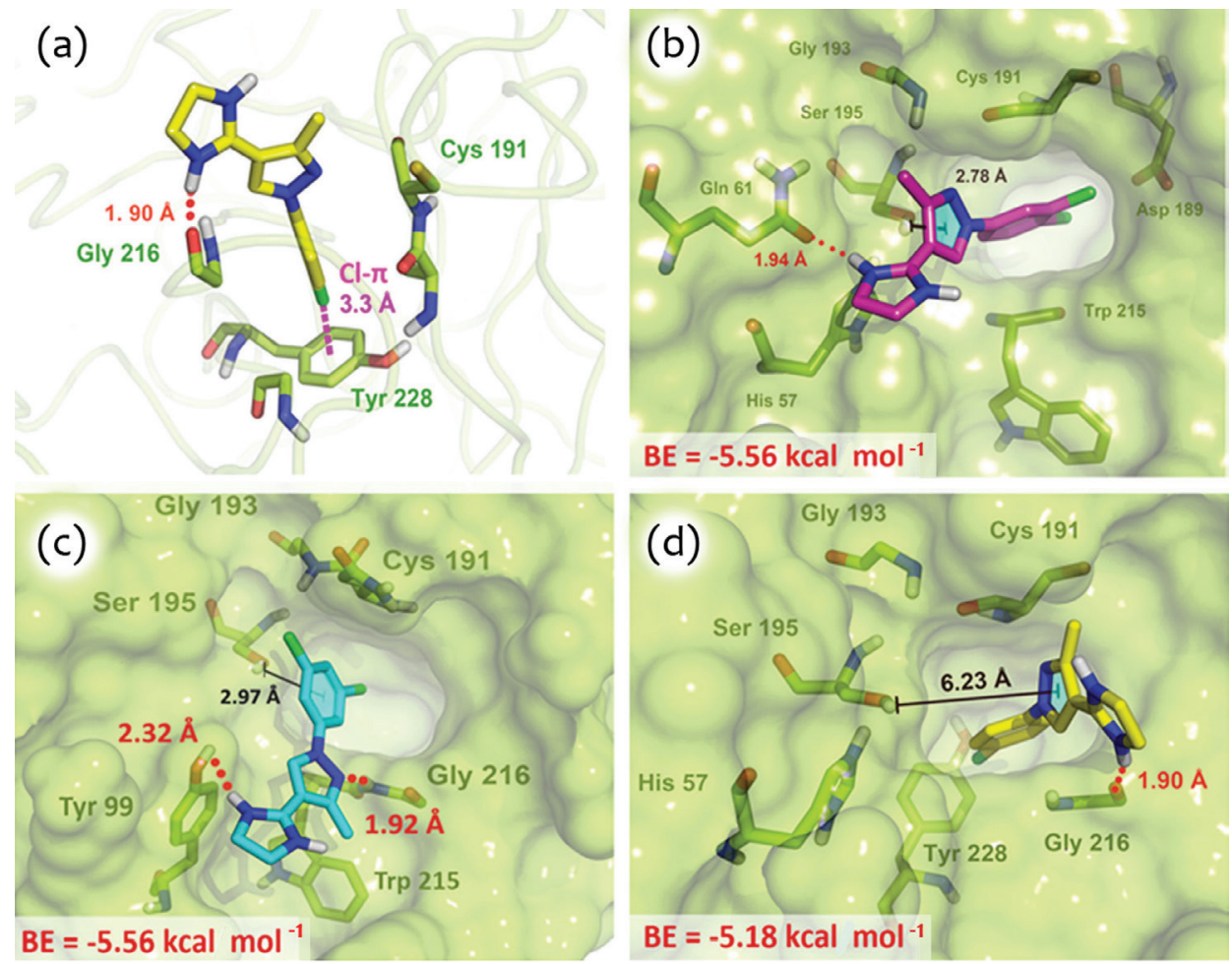

Figure 8. Molecular docking models of (a) $\mathbf{5 d}$, yellow; (b) $\mathbf{5 c}$, pink; and (c) $\mathbf{5 b}$, cyan with human FXa (2JKH). Similar binding modes are observed for the lowest energy scores for $\mathbf{5} \mathbf{d}$ and $\mathbf{5} \mathbf{c}$ with the insertion of the chlorine-substituted phenyl rings to the $S 1$ pocket of the enzyme, where a distinctive chloro- $\pi$ interaction (magenta) is feasible. Such insertion is supported by tight H-bonds (red) between the imidazoline moiety of both molecules with residues Gly216 and glutamine (Gln)61 from the S2 pocket located right at the entrance of S1. Molecule $\mathbf{5 b}$ diverges from its analogues at the lowest energy cluster by adopting a stable conformation maintained by two H-bonds in both S2 and S4 pockets with Gly216 and Tyr99, respectively. The proximity of the pyrazole or phenyl rings from the molecules to the enzyme nucleophile Ser195 is suggestive of a feasible inhibitory modulation by the fragments.

vascular regulators such as naphazoline, xymetazoline, xylometazoline and clonidine. ${ }^{51,52}$ Recently antazoline, another 4,5-dihydro- $1 H$-imidazolyl drug, was reported to safely and rapidly convert atrial fibrillation into a more organized atrial activity, ${ }^{53}$ which reinforces the potential of imidazoline-bearing compounds as cardioprotective agents.

Analysis of theoretical toxicity risks calculated in Osiris Property Explorer revealed that all 4,5-dihydro$1 \mathrm{H}$-imidazolyl pyrazole derivatives $(\mathbf{5 a}-\mathbf{g})$ present low risk

(a)

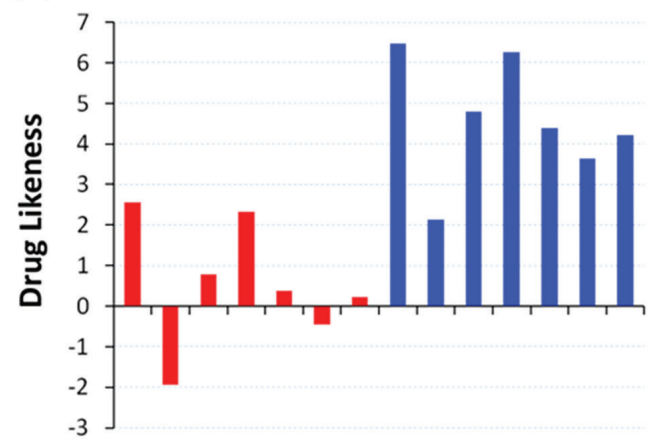

1a 1 b 1c 1d 1e 1 f $1 \mathrm{~g} 5 \mathrm{a} 5 \mathrm{~b} 5 \mathrm{c} 5 \mathrm{~d} 5 \mathrm{e} 5 \mathrm{~g}$ to develop irritant, mutagenic, tumorigenic or reproductive effects; except for the molecule 5c, which presented medium risk to develop reproductive effects (Figure 10). This fragment-based risk score may be derived from 3,4-dichloraniline, used as a building block for the synthesis of $\mathbf{5 c}$ and recently reported as toxic to the reproductive system of male rats. ${ }^{54}$ However, the cyclization reaction of the aniline results in a non-reactive pyrazole ring, which could aid the safety profile of $\mathbf{5 c}$. (b)

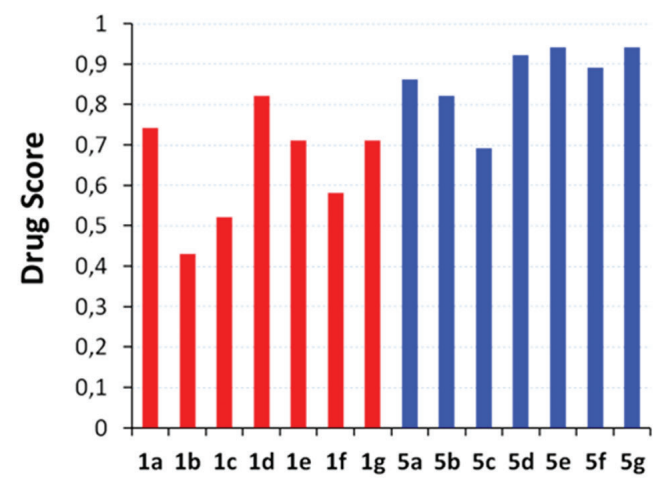

Figure 9. (a) Comparison of fragment-based drug likeness of 4,5-dihydro- $1 H$-imidazolyl pyrazoles (5a-g) and pyrazolyl-1H-tetrazole derivatives (1a-g) obtained from Osiris Property Explorer; (b) comparison of overall drug score between 4,5-dihydro-1H-imidazolyl pyrazoles (5a-g) and pyrazolyl$1 H$-tetrazole series (1a-g). 


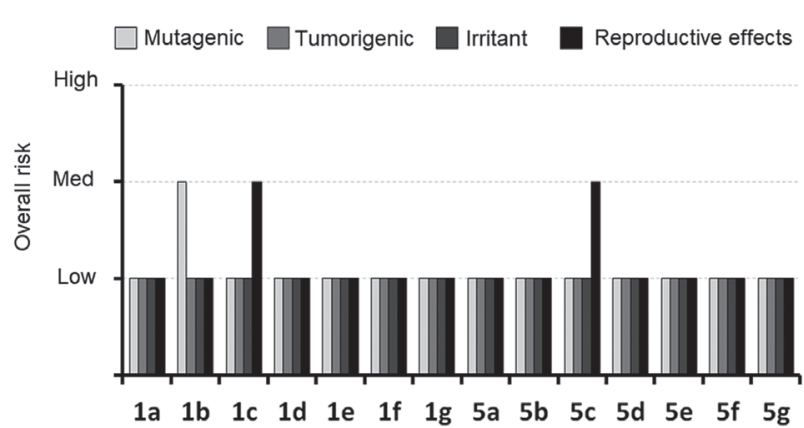

Figure 10. Comparison of theoretical toxicity risks scores of pyrazolyl$1 H$-tetrazole (1a-g) series and 4,5-dihydro- $1 H$-imidazolyl pyrazoles (5a-g) series calculated in a fragment-based approach using Osiris Property Explorer software.

\section{Coagulation assays}

To evaluate the efficacy of the method described above we evaluated the anticoagulant profile of the series of novel 4,5-dihydro- $1 H$-imidazolyl pyrazoles derivatives (5a-g) in the intrinsic and extrinsic pathways of the coagulation cascade, through activated partial thromboplastin time (APTT) and prothrombin time (PT) assays, respectively. Our results revealed that none of the derivatives presented a significant influence on the intrinsic pathway of the coagulation cascade through the APTT assay at screening concentration $(100 \mu \mathrm{M})$ (Figure 11a). In contrast, the results of PT assays showed a mild inhibitory effect of the compounds $\mathbf{5 b}$ and $\mathbf{5 c}$ that was statistically significant, thus identifying both molecules as hits able to improve the overall clotting time (Figure 11b). Further analysis revealed that all molecules identified as potential hits by the tandem structure-activity relationship (SAR)-docking analysis presented a dose-dependent activity profile at PT assays, indicating a concentration able to double the normal prothrombin time $\left(\mathrm{CT}_{2}\right)$ at the micromolar range (5b: $191.3 \pm 4.98 \mu \mathrm{M}$; 5c: $163.1 \pm 4.9 \mu \mathrm{M})$ with good correlation to in silico results (Figure 11c). No increase of the APTT was observed for any active substance even at higher concentrations (SI section, Table S4), revealing a selective influence of the active molecules at the extrinsic pathway of the coagulation cascade, measured preferably by PT assays. Recent studies on clinical assessment of novel anticoagulants impacts on patients report that PT assays are insensitive or little affected by direct thrombin inhibitors such as dabigatran. ${ }^{55,56}$ However, PT is a useful test to access with greater sensitivity the coagulation status in patients receiving $\mathrm{FXa}$ inhibitors, such as rivaroxaban or apixaban, which have a linear dose-response behavior (a)

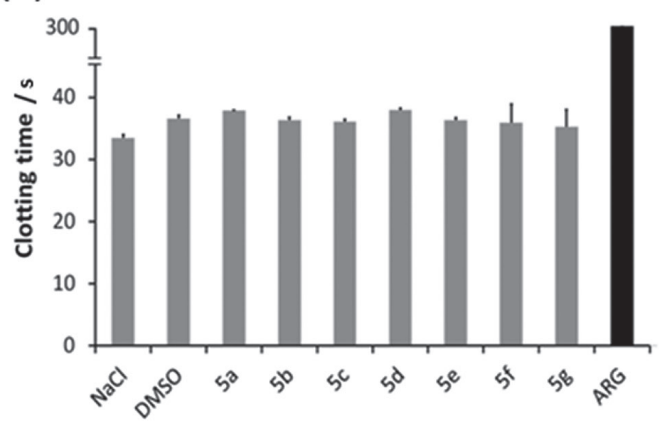

(c)

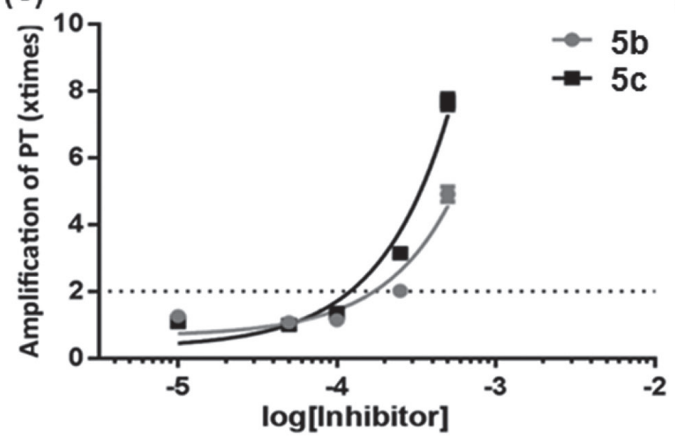

(b)

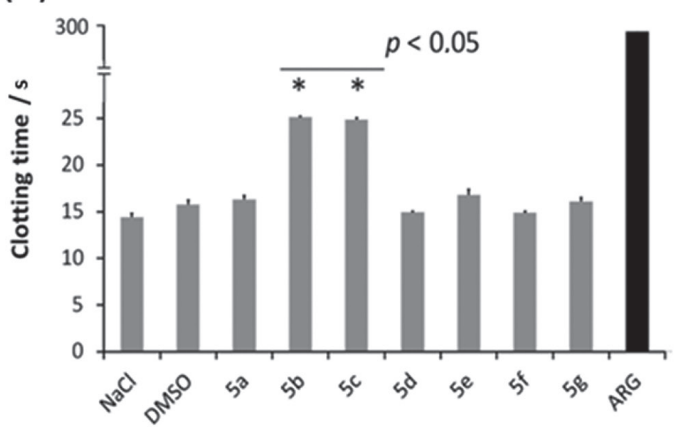

(d)

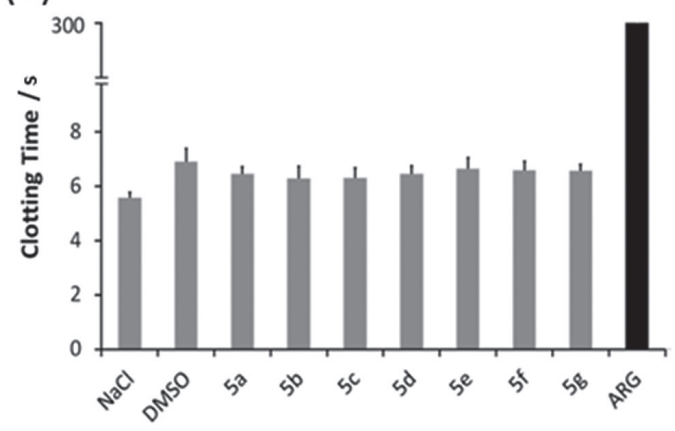

Figure 11. Anticoagulant activity screening assays for all 4,5-dihydro- $1 H$-imidazolyl pyrazoles derivatives $(\mathbf{5 a - g})$ in human pooled plasma (n = 6). (a) APTT and (b) PT were obtained for treated human plasma as well as the (c) clotting time $\times 2$ factor $\left(\mathrm{CT}_{2}\right)$ determined for both $\mathbf{5 b}$ and $\mathbf{5} \mathbf{c}$ as the concentration necessary to double the normal coagulation time. At $1 \mathrm{mM}$ both compounds hit the $\mathrm{CT}_{2}$ threshold of 10 -fold, which was assumed as an endpoint for titration. (d) TT was also performed to evaluate the overall thrombin activity. All molecules were initially screened at final concentration of $100 \mu \mathrm{M}$, with quantitative dose-response curves being carried out only for the most active compounds. Saline solution ( $0.15 \mathrm{M} \mathrm{NaCl),} \mathrm{dimethyl} \mathrm{sulfoxide} \mathrm{(DMSO;} 1 \%$ ) and thrombin selective inhibitor argatroban (ARG; $100 \mu \mathrm{M})$ were used as controls. 
despite the variability in PT reagents. ${ }^{57,58}$ Our experimental results show how the newly in silico designed pyrazoleimidazoline compounds present a similar behavior to direct FXa inhibitors, with dose-response curves detectable by routine coagulation tests of PT and APTT.

The thrombin time (TT) assay displays a linear-dose response to thrombin direct inhibitors (dabigatran), but is insensitive to FXa inhibitors. ${ }^{59}$ TT was, therefore, performed to evaluate the potential of novel pyrazoleimidazoline derivatives as thrombin inhibitors. ${ }^{60}$ Our results show that none of the derivatives showed a statistically significant variation in the clotting time of human plasma, revealing that no clinically relevant thrombin inhibition was observed (Figure 11d).

\section{Chromogenic assays}

Although human thrombin and FXa share great structural similarities, both hit molecules $\mathbf{5 b}$ and $\mathbf{5 c}$ were not able to inhibit human thrombin activity over the thrombinspecific (S-2238) chromogenic substrate (Figures 12a and 12b). No significant inhibitory activity was observed for compound $\mathbf{5 b}$ against human FXa cleavage of FXa-specific (S-2765) substrate (SI section, Figure S1). On the other hand, the results from human FXa kinetics over its specific substrate S-2765 revealed that the hit compound $\mathbf{5 c}$ is able to cause dose-dependent inhibition of the enzyme at optimal pH (Figure 12c) with a half maximal inhibitory concentration $\left(\mathrm{IC}_{50}\right.$ ) value of $142.8 \pm 85 \mu \mathrm{M}$ (Figure $12 \mathrm{~d}$ ). Michaelis-Menten kinetics show that reduced initial velocity of human FXa is observed by increasing the concentration of 5c (Figure 12e) that binds to the enzyme with an inhibition constant $(\mathrm{Ki})$ value of $61.16 \pm 12.96 \mu \mathrm{M}$ and a ligand efficiency of $0.31 \mathrm{kcal} \mathrm{mol}^{-1}$. Double-reciprocal Lineweaver-Burk plots reveal that the molecule behaves as a uncompetitive inhibitor, whose mode of action is based on active binding to the enzyme-substrate complex but not the enzyme alone (Figure 12f). ${ }^{61}$

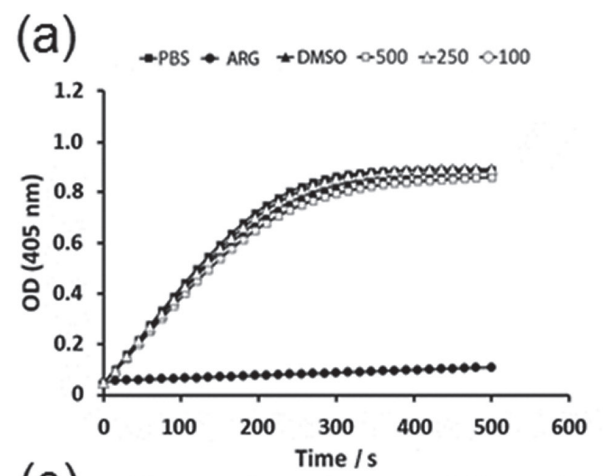

(c)

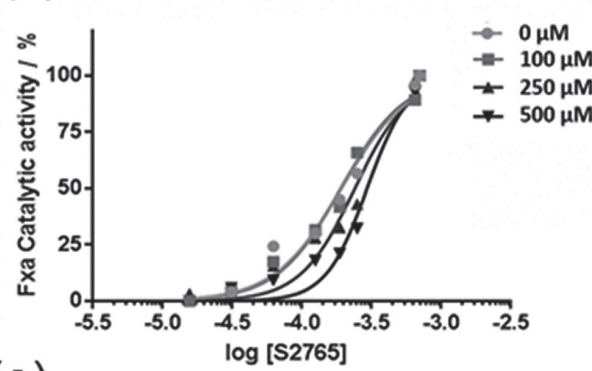

(e)

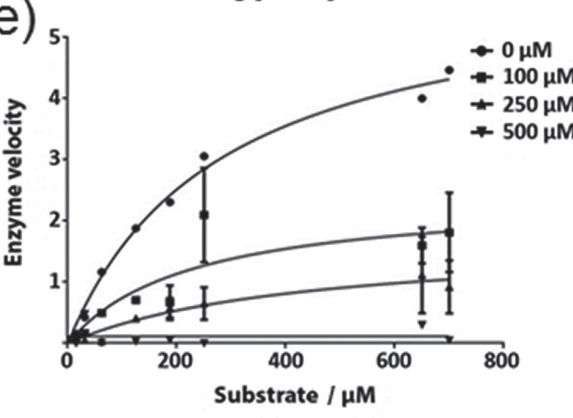

(b)

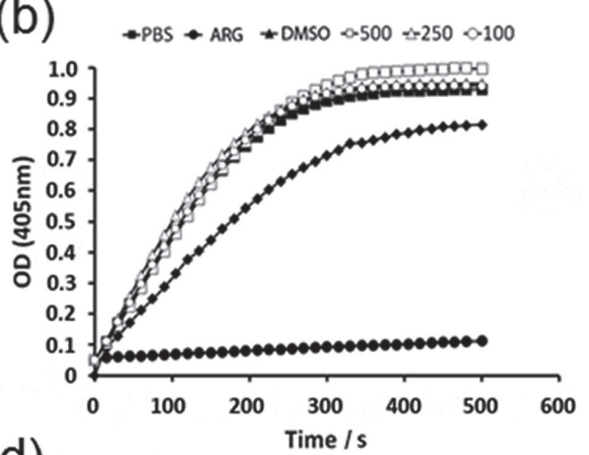

(d)

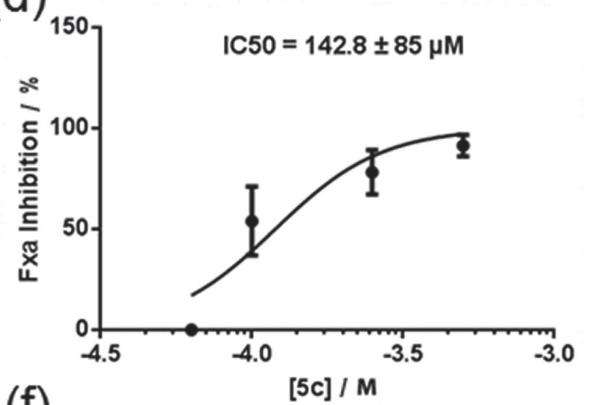

(f)

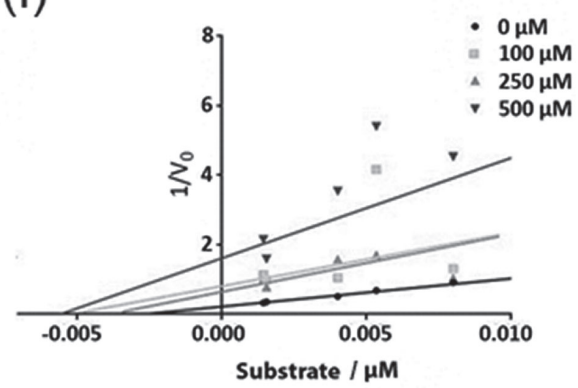

Figure 12. Thrombin activity over the chromogenic substrate $S-2238$ is not impaired by compounds (a) $\mathbf{5 b}$ or (b) $\mathbf{5} \mathbf{c}$ at any tested concentration. Dosedependent inhibition of FXa chromogenic activity over S-2765 is observed in the presence of (c) $\mathbf{5}$, which displays (d) an $\mathrm{IC}_{50}$ value of $142.8 \pm 85 \mu \mathrm{M}$. Michaelis-menten kinetics revealed active binding to human FXa with (e) a Ki of $61.16 \pm 12.96 \mu \mathrm{M}$ and (f) an uncompetitive mode of inhibition. 


\section{Toxicological assays}

Literature describes several reports that suggest a direct relationship between the lipophilicity of a molecule and its hemolytic potential. According to Kleszczynska et al. ${ }^{62}$ the result from the hemolysis assay reveals that no detectable traces of hemoglobin were released from healthy human erythrocytes after $3 \mathrm{~h}$ of treatment with each test molecule. These results support the low toxicological risk associated with these new series of compounds (Table 2) and prompt for in vivo evaluation of efficacy.

Table 2. Hemolytic activity of novel 4,5-dihydro- $1 H$-imidazolyl derivatives (5a-g) on healthy human red blood cells

\begin{tabular}{lc}
\hline Compound & Hemolysis / \% \\
\hline $1 \%$ DMSO & $0 \pm 0.17$ \\
5a & $0 \pm 0.18$ \\
$\mathbf{5 b}$ & $0 \pm 0.07$ \\
$\mathbf{5 c}$ & $0 \pm 0.06$ \\
$\mathbf{5 d}$ & $0 \pm 0.2$ \\
$\mathbf{5 e}$ & $0 \pm 0.59$ \\
$\mathbf{5 f}$ & $0 \pm 0.11$ \\
$\mathbf{5 g}$ & $0 \pm 0.08$ \\
Triton X-100 & $100 \pm 9.31$
\end{tabular}

DMSO: dimethyl sulfoxide.

\section{In vivo antithrombotic activity}

After identifying the compound $\mathbf{5 c}$ with FXa-specific inhibitory activity, in vitro anticoagulant activity, and low hemolytic potential, we decided to test the power of our virtual screening algorithm by evaluating the in vivo antithrombotic activity of the hit molecule 5c. Mice treated with $\mathbf{5 c}\left(10 \mathrm{mg} \mathrm{kg}^{-1}\right)$ were sedated and submitted to surgical exposure of the carotid artery $20 \mathrm{~min}$ after drug administration. Oral gavage was chosen as the most favorable administration route as in silico results point to the good oral bioavailability of the compound. Acute arterial thrombosis, triggered by $\mathrm{FeCl}_{3}$, was shown to be successfully attenuated by the treatment with $\mathbf{5 c}$ (Figure 13). This result indicates the power of the algorithm described herein for the identification of novel oral anticoagulants fragments, whose activity can be tracked both in vitro and in vivo.

\section{Conclusions}

IMA-VS describes the combination of common virtual screening strategies into a single in silico pipeline. Overall, our data supports the usage of IMA-VS in the discovery

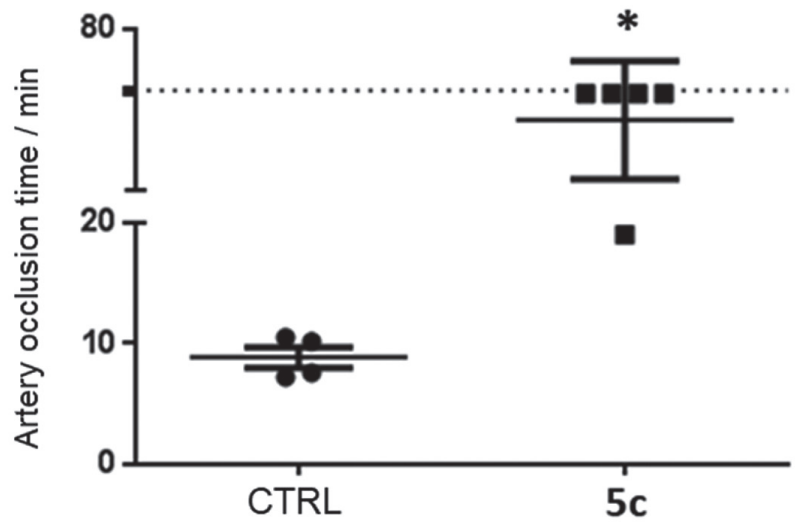

Figure 13. In vivo antithrombotic activity of compound $\mathbf{5 c}\left(10 \mathrm{mg} \mathrm{kg}^{-1}\right)$ in a murine model of $\mathrm{FeCl}_{3}$-induced arterial thrombosis. CTRL: control.

of novel anticoagulants with enzyme-specific activity, in vitro anticoagulant activity in human plasma, low toxicity over human red blood cells and antithrombotic activity in a murine model of arterial thrombosis. Through the identification of the lead anticoagulant compound 5c from a small target-focused library, this work supports the combined usage of structure-based and ligand-based computer aided drug discovery campaigns with the aid of prior physicochemical evaluation and lead-likeness filters, into one powerful tool for the design and synthesis of novel anticoagulant lead compounds.

\section{Experimental}

\section{Chemistry}

All reagents and solvents were used as obtained from commercial sources. The reaction progress was monitored by thin layer chromatography (TLC). Fourier transform (FT) infrared (IR) spectra were obtained from a Spectrum Two IR Spectrometer (PerkinElmer) instrument. The nuclear magnetic resonance (NMR) spectra were recorded on a Varian VNMRS of 300 or $500 \mathrm{MHz}$ with a $11.75 \mathrm{~T}$ magnet. Chemical shifts are expressed in parts per million (ppm) and coupling constants are given in Hz. Further characterization was performed on an Agilent 6890 gas chromatograph (GC) coupled with an Agilent 5973B electrospray ionization (ESI) high resolution mass spectrometer (HRMS). Samples were injected using an Agilent autosampler unit into an Agilent 122-5532 DB$5 \mathrm{MS}$ column at a temperature range from 50 to $350{ }^{\circ} \mathrm{C}$.

General procedure for the synthesis of 5-(1-aryl-3-methyl$1 H$-pyrazol-4-yl)-1H-tetrazole (1a-g)

The synthetic route to obtain the pyrazolyl- $1 H$-tetrazoles derivatives was previously described by our research group. ${ }^{27}$ 
5-[1-(2',4'-Dichlorophenyl)-3-methyl-1H-pyrazol-4-yl]$1 \mathrm{H}$-tetrazole (1a)

Yield 50\%; mp 217-220 ${ }^{\circ} \mathrm{C}$; IR (KBr) $\mathrm{v} / \mathrm{cm}^{-1}$ 3397-2700, 1607, 1516, 1489, 1452, 1389, 1347, 1210, 1107, 1006, 950, 858, 809, 747; ' ${ }^{1} \mathrm{H}$ NMR $(300 \mathrm{MHz}$, DMSO- $\left._{6}\right) \delta 2.56(\mathrm{~s}, 3 \mathrm{H}), 7.59(\mathrm{dd}, J 8.6,2.3,1 \mathrm{H}), 7.69$ $(\mathrm{d}, J$ 8.6, $1 \mathrm{H}), 7.83(\mathrm{~d}, J 2.3,1 \mathrm{H}), 8.68(\mathrm{~s}, 1 \mathrm{H}) ;{ }^{13} \mathrm{C} \mathrm{NMR}$ $\left(75 \mathrm{MHz}, \mathrm{DMSO}-d_{6}\right) \delta 13.1,107.9,128.4,128.5,129.0$, 130.0, 132.5, 133.6, 136.2, 148.6, 150.4; HRMS (ESI) [M $-\mathrm{H}]^{-}$calcd.: 293.0109; found: 293.0118.

5-[1-(3',5'-Dichlorophenyl)-3-methyl-1 H-pyrazol-4-yl]$1 \mathrm{H}$-tetrazole (1b)

Yield 70\%; mp 242-244 ${ }^{\circ} \mathrm{C}$; IR (KBr) $v / \mathrm{cm}^{-1}$ 3200-2724, 1612, 1581, 1532, 1470, 1435, 1391, 1340, 1226, 1123, 1067, 1010, 977, 882, 838, 815, 790, 745; ${ }^{1} \mathrm{H}$ NMR $\left(500 \mathrm{MHz}\right.$, DMSO- $\left.d_{6}\right) \delta 2.53(\mathrm{~s}, 3 \mathrm{H}), 7.53$ (t, $J 1.8,1 \mathrm{H}), 7.94(\mathrm{~d}, J 1.8,2 \mathrm{H}), 9.02(\mathrm{~s}, 1 \mathrm{H}) ;{ }^{13} \mathrm{C} \mathrm{NMR}$ $\left(125 \mathrm{MHz}, \mathrm{DMSO}-d_{6}\right) \delta 13.4,110.4,116.7,125.5,128.6$, 135.1, 140.8, 149.6, 151.4; HRMS (ESI) [M - H] ${ }^{-}$calcd.: 293.0109; found: 293.0120 .

5-[1-(3',4'-Dichlorophenyl)-3-methyl-1H-pyrazol-4-yl]$1 H$-tetrazole (1c)

Yield 72\%; mp 228-230 ${ }^{\circ} \mathrm{C}$; IR ( $\left.\mathrm{KBr}\right) \mathrm{v} / \mathrm{cm}^{-1} 3404-$ 2585, 1622, 1593, 1536, 1488, 1448, 1356, 1242, 1134, 1065, 1003, 965, 878, 806, 746; ${ }^{1} \mathrm{H}$ NMR $(500 \mathrm{MHz}$, DMSO- $\left._{6}\right) \delta 2.65(\mathrm{~s}, 3 \mathrm{H}), 7.86(\mathrm{~d}, J 8.8,1 \mathrm{H}), 7.94(\mathrm{dd}$, $J$ 8.8, 2.5, 1H), $8.21(\mathrm{~d}, J 2.5,1 \mathrm{H}), 9.11(\mathrm{~s}, 1 \mathrm{H}) ;{ }^{13} \mathrm{C} \mathrm{NMR}$ $\left(125 \mathrm{MHz}, \mathrm{DMSO}-d_{6}\right) \delta 13.3,108.5,118.4,120.1,128.9$, 129.0, 131.6, 132.2, 138.5, 149.5, 150.4; HRMS (ESI) $[\mathrm{M}-\mathrm{H}]^{-}$calcd.: 293.0109; found: 293.0117.

5-[1-(4'-Chlorophenyl)-3-methyl-1H-pyrazol-4-yl]$1 \mathrm{H}$-tetrazole (1d)

Yield 52\%; mp 232-234 ${ }^{\circ} \mathrm{C}$; IR $(\mathrm{KBr}) \mathrm{v} / \mathrm{cm}^{-1}$ 3425-2672, 1619, 1594, 1499, 1439, 1381, 1359, 1210, 1095, 1060, 1002, 951, 822, 747; ' ${ }^{\mathrm{H}} \mathrm{NMR}(500 \mathrm{MHz}$, DMSO- $\left.d_{6}\right) \delta 2.67(\mathrm{~s}, 3 \mathrm{H}), 7.67(\mathrm{~d}, J 8.8,2 \mathrm{H}), 7.97(\mathrm{~d}, J 8.8$, $2 \mathrm{H}), 9.03(\mathrm{~s}, 1 \mathrm{H}) ;{ }^{13} \mathrm{C}$ NMR (125 MHz, DMSO- $\left.d_{6}\right) \delta 13.3$, 109.1, 120.0, 128.1, 129.5, 130.7, 137.9, 148.9, 151.0; HRMS (ESI) [M - H] $]^{-}$calcd.: 259.0499; found: 259.0508.

5-[1-(4'-Fluorophenyl)-3-methyl-1 H-pyrazol-4-yl]$1 \mathrm{H}$-tetrazole (1e)

Yield 52\%; mp 228-232 ${ }^{\circ} \mathrm{C}$; IR (KBr) v / $\mathrm{cm}^{-1} 3380-$ 2542, 1611, 1520, 1501, 1454, 1384, 1364, 1231, 1162, $1060,1005,955,828,746 ;{ }^{1} \mathrm{H}$ NMR $\left(500 \mathrm{MHz}\right.$, DMSO- $\left.d_{6}\right)$ $\delta 2.54$ (s, 3H), 7.34 (t, $J 8.8,2 \mathrm{H}), 7.86(\mathrm{dd}, J 8.8,4.4,2 \mathrm{H})$, $8.80(\mathrm{~s}, 1 \mathrm{H}) ;{ }^{13} \mathrm{C}$ NMR $\left(125 \mathrm{MHz}\right.$, DMSO- $\left.d_{6}\right) \delta 13.4,110.2$, 116.3 (d, $J$ 22.9), 120.3 (d, $J$ 8.4), 127.6, 135.9 (d, $J$ 2.6),
148.5, 151.8, 160.3 (d, $J$ 241.8); HRMS (ESI) $[\mathrm{M}-\mathrm{H}]^{-}$ calcd.: 243.0794; found: 243.0802 .

5-[1-(4'-Bromophenyl)-3-methyl-1H-pyrazol-4-yl]$1 \mathrm{H}$-tetrazole (1f)

Yield 61\%; mp 210-213 ${ }^{\circ} \mathrm{C}$; IR $(\mathrm{KBr}) \mathrm{v} / \mathrm{cm}^{-1}$ 3130-2665, 1614, 1589, 1532, 1495, 1451, 1410, 1353, 1211, 1148, 1076, 1057, 1005, 990, 951, 816, 747; ${ }^{1} \mathrm{H}$ NMR $\left(500 \mathrm{MHz}, \mathrm{DMSO}-d_{6}\right) \delta 2.66(\mathrm{~s}, 3 \mathrm{H}), 7.82(\mathrm{~d}, J 9.0,2 \mathrm{H})$, $7.91\left(\mathrm{~d}, J\right.$ 9.0, 2H), $9.03(\mathrm{~s}, 1 \mathrm{H}) ;{ }^{13} \mathrm{C}$ NMR $(125 \mathrm{MHz}$, DMSO- $\left.d_{6}\right) \delta 13.2,107.6,119.0,119.2,120.4,128.6,132.5$, 138.1, 149.0; HRMS (ESI) [M - H] $]^{-}$calcd.: 302.9994; found: 302.9999 .

5-[1-(4'-Methoxyphenyl)-3-methyl-1H-pyrazol-4-yl]$1 \mathrm{H}$-tetrazole $(\mathbf{1 g})$

Yield 70\%; mp 245-247 ${ }^{\circ} \mathrm{C}$; IR $(\mathrm{KBr}) \mathrm{v} / \mathrm{cm}^{-1}$ 3229, 2625, 1618, 1565, 1534, 1501, 1438, 1380, 1238, $1225,1167,1062,1005,1048,823,745 ;{ }^{1} \mathrm{H}$ NMR $\left(500 \mathrm{MHz}, \mathrm{DMSO}-d_{6}\right) \delta 2.65(\mathrm{~s}, 3 \mathrm{H}), 3.92(\mathrm{~s}, 3 \mathrm{H}), 7.19$ (d, $J$ 9.0, 2H), $7.84(\mathrm{~d}, J 9.0,2 \mathrm{H}), 8.87(\mathrm{~s}, 1 \mathrm{H}) ;{ }^{13} \mathrm{C} \mathrm{NMR}$ $\left(125 \mathrm{MHz}, \mathrm{DMSO}-d_{6}\right) \delta 13.2,55.5,106.6,114.8,120.3$, 128.3 132.6, 148.2, 158.2; HRMS (ESI) $[\mathrm{M}-\mathrm{H}]^{-}$calcd.: 255.0994; found: 255.1003 .

General procedure for the synthesis of 1-aryl-4-(4,5-dihydro$1 H$-imidazol-2-yl)-3-methyl- $1 H$-pyrazoles (5a-g)

A mixture of the key intermediates 1-aryl-3-methyl$1 \mathrm{H}$-pyrazole-4-carbonitriles $(\mathbf{4 a - g})(0.002 \mathrm{~mol})$ and ethylenediamine $(5 \mathrm{~mL})$ was cooled to $0{ }^{\circ} \mathrm{C}$. Carbon disulfide ( 8 drops) was added dropwise and the reaction mixture was heated under reflux for $17 \mathrm{~h}$. After this time, the reaction mixture was poured onto crushed ice. The resulting solid was filtered out, washed with cold water and recrystallized from ethanol/water.

1-(2',4'-Dichlorophenyl)-4-(4,5-dihydro-1 H-imidazol-2-yl)3-methyl-1 $\mathrm{H}$-pyrazole (5a)

Yield 50\%; mp 80-82 ${ }^{\circ} \mathrm{C}$; IR (KBr) $v / \mathrm{cm}^{-1} 3186,3087$, 3051, 2984, 2948, 2849, 1614, 1566, 1526, 1466, 1285, 1186, 1100, 950, 795; ${ }^{1} \mathrm{H}$ NMR (300 MHz, DMSO- $\left.d_{6}\right)$ $\delta 2.39(\mathrm{~s}, 3 \mathrm{H}), 3.61(\mathrm{~s}, 1 \mathrm{H}), 3.68(\mathrm{~s}, 4 \mathrm{H}), 7.70(\mathrm{dd}, J 8.8,2.0$, $1 \mathrm{H}), 7.77(\mathrm{~d}, J 8.8,1 \mathrm{H}), 7.98(\mathrm{~d}, J 2.0,1 \mathrm{H}), 8.52(\mathrm{~s}, 1 \mathrm{H})$; ${ }^{13} \mathrm{C}$ NMR $\left(75 \mathrm{MHz}\right.$, DMSO- $d_{6}$ ) $\delta 13.6,49.1,112.7,128.3$, 128.4, 129.0, 130.0, 132.9, 133.4, 136.3, 149.4, 158.5; HRMS (ESI) $[\mathrm{M}+\mathrm{H}]^{+}$calcd. 295.0517; found: 295.0523.

1-(3',5'-Dichlorophenyl)-4-(4,5-dihydro-1 H-imidazol-2-yl)3-methyl-1 $\mathrm{H}$-pyrazole $(\mathbf{5 b})$

Yield 67\%; mp 180-182 ${ }^{\circ} \mathrm{C}$; IR (KBr) v / $\mathrm{cm}^{-1} 3213$, 3126, 3098, 2972, 2940, 2873, 1618, 1590, 1577, 1540, 
1514, 1329, 1278, 1119, 1071, 838, 803, 789; ${ }^{1} \mathrm{H}$ NMR $\left(500 \mathrm{MHz}, \mathrm{DMSO}-d_{6}\right) \delta 2.57(\mathrm{~s}, 3 \mathrm{H}), 3.68(\mathrm{~s}, 4 \mathrm{H}), 7.64$ $(\mathrm{t}, J 1.8,1 \mathrm{H}), 7.95(\mathrm{~d}, J 1.8,2 \mathrm{H}), 8.95(\mathrm{~s}, 1 \mathrm{H}) ;{ }^{13} \mathrm{C} \mathrm{NMR}$ $\left(125 \mathrm{MHz} \mathrm{CDCl}_{3}\right) \delta 13.8,49.9,114.5,117.1,126.3,127.5$, 135.9, 140.8, 150.4, 158.7; HRMS (ESI) $[\mathrm{M}+\mathrm{H}]^{+}$calcd.: 295.0517; found: 295.0526 .

1-(3',4'-Dichlorophenyl)-4-(4,5-dihydro-1H-imidazol-2-yl)3-methyl-1 $\mathrm{H}$-pyrazole (5c)

Yield 73\%; mp 105-107 ${ }^{\circ} \mathrm{C}$; IR (KBr) v / $\mathrm{cm}^{-1} 3226$, 3126, 3101, 2971, 2940, 2869, 1318, 1590, 1540, 1516, 1483, 1378, 1216, 1119, 1024, 969, 804; ${ }^{1} \mathrm{H}$ NMR $\left(500 \mathrm{MHz}, \mathrm{DMSO}-d_{6}\right) \delta 2.56(\mathrm{~s}, 3 \mathrm{H}), 3.67$ (s, 4H), 7.85-7.88 (m, 2H), 8.12-8.14 (m, 1H), $8.87(\mathrm{~s}, 1 \mathrm{H})$; ${ }^{13} \mathrm{C}$ NMR (125 MHz, DMSO- $\left.d_{6}\right) \delta 13.7,49.3,114.2$, $118.1,119.7,128.5,129.1,131.6,132.2,138.8,150.3$, 158.6; HRMS (ESI) $[\mathrm{M}+\mathrm{H}]^{+}$calcd.: 295.0517; found: 295.0519 .

1-(4'-Chlorophenyl)-4-(4,5-dihydro-1 H-imidazol-2-yl)3-methyl-1 $\mathrm{H}$-pyrazole (5d)

Yield 83\%; mp 168-170 ${ }^{\circ} \mathrm{C}$; IR (KBr) v / $\mathrm{cm}^{-1} 3204$, 3130, 3099, 3067, 2971, 2892, 2860, 1613, 1596, 1514, $1495,1367,1217,1122,1091,985,951,840 ;{ }^{1} \mathrm{H}$ NMR $\left(500 \mathrm{MHz}, \mathrm{DMSO}-d_{6}\right) \delta 2.57(\mathrm{~s}, 3 \mathrm{H}), 3.66(\mathrm{~s}, 4 \mathrm{H}), 7.68$ $(\mathrm{d}, J 9.0,2 \mathrm{H}), 7.89(\mathrm{~d}, J 9.0,2 \mathrm{H}), 8.81(\mathrm{~s}, 1 \mathrm{H}) ;{ }^{13} \mathrm{C} \mathrm{NMR}$ $\left(125 \mathrm{MHz}, \mathrm{DMSO}-d_{6}\right) \delta 13.7,49.3,113.9,119.8,128.6$, 129.6, 130.4, 138.0, 149.8, 158.6; HRMS (ESI) $[\mathrm{M}+\mathrm{H}]^{+}$ calcd.: 261.0917; found: 261.0916.

1-(4'-Fluorophenyl)-4-(4,5-dihydro-1 H-imidazol-2-yl)3-methyl-1 $\mathrm{H}$-pyrazole (5e)

Yield 64\%; mp 168-170 ${ }^{\circ} \mathrm{C}$; IR (KBr) v / $\mathrm{cm}^{-1} 3219$, 3130, 3067, 2948, 2892, 2869, 1618, 1519, 1505, 1448, 1270, 1222, 1120, 985, 828; ${ }^{1} \mathrm{H}$ NMR (300 MHz, DMSO- $\left.d_{6}\right) \delta 2.46(\mathrm{~s}, 3 \mathrm{H}), 3.56(\mathrm{~s}, 4 \mathrm{H}), 7.32(\mathrm{t}, J 9.8,2 \mathrm{H})$, 7.77 (dd, $J 9.8,4.8,2 \mathrm{H}), 8.60(\mathrm{~s}, 1 \mathrm{H}) ;{ }^{13} \mathrm{C} \mathrm{NMR}(75 \mathrm{MHz}$, DMSO- $\left.d_{6}\right) \delta 13.9,49.7,14.1,116.6$ (d, $J$ 22.9), 120.6 (d, J 9.6), 128.9, 136.3, 149.8, 158.9, 161.0 (d, J 243.2); HRMS (ESI) $[\mathrm{M}+\mathrm{H}]^{+}$calcd.: 245.1202; found: 245.1240 .

1-(4'-Bromophenyl)-4-(4,5-dihydro-1 H-imidazol-2-yl)3-methyl-1 $\mathrm{H}$-pyrazole (5f)

Yield 85\%; mp 154-156 ${ }^{\circ} \mathrm{C}$; IR (KBr) v / cm $\mathrm{cm}^{-1} 3199$, 3130, 3095, 2972, 2940, 2854, 1614, 1590, 1516, $1491,1366,1216,1122,1072,984,951,821 ;{ }^{1} \mathrm{H}$ NMR $\left(300 \mathrm{MHz}, \mathrm{DMSO}-d_{6}\right) \delta 2.46(\mathrm{~s}, 3 \mathrm{H}), 3.57$ (s, 4H), 7.64$7.74(\mathrm{~m}, 4 \mathrm{H}), 8.66(\mathrm{~s}, 1 \mathrm{H}) ;{ }^{13} \mathrm{C} \mathrm{NMR}\left(75 \mathrm{MHz}, \mathrm{DMSO}-d_{6}\right)$ $\delta 14.0,49.7,114.4,118.9,120.5,128.8,132.8,138.9$, 150.2, 158.8; HRMS (ESI) $[\mathrm{M}+\mathrm{H}]^{+}$calcd.: 305.0402; found: 305.0411 .
1-(4'-Methoxyphenyl)-4-(4,5-dihydro-1 H-imidazol-2-yl)3-methyl-1 $\mathrm{H}$-pyrazole $\mathbf{( 5 g})$

Yield 55\%; mp 97-99 ${ }^{\circ} \mathrm{C}$; IR (KBr) v / $\mathrm{cm}^{-1} 3261,3138$, 3071, 3003, 2972, 2933, 2892, 2865, 2837, 1624, 1545, 1517, 1501, 1442, 1301, 1242, 1107, 1028, 986, 835; ${ }^{1} \mathrm{H}$ NMR (300 MHz, DMSO- $\left.d_{6}\right) \delta 2.56(\mathrm{~s}, 3 \mathrm{H}), 3.56$ (s, 4H), 3.80 (s, 3H), 7.05 (d, J 9.1, 2H), 7.65 (d, J 9.1, 2H), $8.52(\mathrm{~s}, 1 \mathrm{H}) ;{ }^{13} \mathrm{C}$ NMR $\left(75 \mathrm{MHz}, \mathrm{DMSO}-d_{6}\right) \delta 13.9,49.7$, 55.9, 113.5, 115.2, 120.8, 128.5, 133.4, 149.2, 158.2, 159.1; HRMS (ESI) $[\mathrm{M}+\mathrm{H}]^{+}$calcd.: 257.1402; found: 257.1409.

Physicochemical, stereoeletronic and bioavailability evaluation

The theoretical study of bioavailability and toxicity properties was performed using Osiris Property Explorer. Additional evaluation of bioavailability for each candidate was performed through Oprea's lead likeness filter. ${ }^{63}$ Instant JChem $^{64}$ was used for structure database management and prediction.

The major species at $\mathrm{pH} 7.4$ of each molecule was verified using Marvin 16.1.4.0, and stereoeletronic properties were calculated using Spartan'10. Briefly, geometry was optimized using Hartree-Fock (HF) method with 3-21G basis set. Subsequently, all derivatives were submitted to a single-point HF energy calculation with 6-31G** basis set, to calculate stereoelectronic properties and perform the SAR studies. Thus, we calculated HOMO and LUMO energies and density isosurface, molecular weight, molecular surface area, polar surface area, dipole moment and electrostatic potential maps. The electronic profile of each molecule was then compared to approved antithrombotic agents.

\section{Structure-based design}

The crystallographic structures of coagulation FXa (Protein Data Bank (PDB) No. 2JKH) and thrombin (PDB No. 3RM2) were obtained from the PDB and prepared using the Dock Prep module available on University of California, San Francisco (UCSF) Chimera. ${ }^{65}$ Briefly, hydrogen atoms were added, solvent was deleted, residues with incomplete side chains were mutated to alanine or glycine and Austin model 1-bond charge correction (AM1-BCC) charges were added. In addition, the targets molecular surfaces were generated with DMS program ${ }^{66}$ with a probe radius of 1.4 ̊̊. Docking experiments were carried using DOCK 6.7 program. ${ }^{67}$ DOCK accessory programs sphgen and sphere selector were used to generate spheres defining the binding sites within $8.0 \AA$ of the crystallographic ligands positions. After sphere generation, DOCK accessory program showbox was used to build a box around the spheres with 
8.0 $\AA$ of extra margin. The program GRID ${ }^{68}$ was used to precompute the energy interactions between molecules and the targets with a $0.3 \AA$ resolution inside the box. Finally, flexible ligand docking was carried considering rigid anchor segments with at least 5 atoms and 1000 anchor orientations. A maximum number of 10 conformers of each ligand were retained for inspection considering a $2.0 \AA$ root mean square deviation (RMSD) cutoff.

\section{Anticoagulant properties evaluation}

For tests of APTT, PT and TT we used pools $(n=6)$ of citrated human plasma samples with no disturbances in the hemostatic system, and international normalized ratio as previously described. ${ }^{69}$ Assays were performed in coagulation analyzer CoagLab IV (Shining Sun) as described according to the manufacturer's instructions (WAMA Diagnostics) with approval from the Universidade Federal Fluminense (UFF) ethics committee protocol No. 621,196. Values of the concentration required to double the normal clotting time $\left(\mathrm{CT}_{2}\right)$ were obtained through the non-linear regression of a dose-response curve with a coefficient of determination value close to $1\left(\mathrm{R}^{2}=0.98\right)$.

\section{Enzymes chromogenic activity}

In the screening assays, all derivatives were incubated for $5 \mathrm{~min}$ at $37{ }^{\circ} \mathrm{C}$ with bovine thrombin $\left(3 \mu \mathrm{g} \mathrm{mL} \mathrm{m}^{-1}\right.$, Sigma-Aldrich) or human FXa ( $3 \mu \mathrm{g} \mathrm{mL}^{-1}$, Haematologica) in a phosphate buffered saline (PBS) solution enriched with $0.025 \mathrm{M}$ calcium chloride at $\mathrm{pH} 7.45$. Chromogenic activities were triggered by the addition of chromogenic substrates S-2238 or S-2765 in a final concentration of $2.5 \mathrm{mM}$. Catalysis kinetics of $p$-nitroaniline was monitored for $20 \mathrm{~min}$ by a SpectraMax 190 microplate reader at $415 \mathrm{~nm}$ wavelength. Apixaban and argatroban were used as controls for FXa and thrombin, respectively. Experimental $\mathrm{IC}_{50}$ values were based on a substrate concentration of $250 \mu \mathrm{M}$ and were obtained by fitting a normalized response of FXa catalytic activity vs. inhibitor concentration to nonlinear regression models using Matlab. ${ }^{70} \mathrm{Ki}$ values of the inhibitory molecules were determined by fitting the initial velocity $v s$. substrate concentration data to nonlinear regression models using the GraphPad Prism software, ${ }^{71}$ The Ki values are expressed as final assay concentrations.

Toxicity profile

Healthy erythrocytes were washed three times with PBS (pH 7.4) by centrifugation and suspension in the same buffer. All derivatives were incubated with the suspension of erythrocytes for $3 \mathrm{~h}$ at $37^{\circ} \mathrm{C}$. The release of hemoglobin was determined by the optical density of the supernatant at $540 \mathrm{~nm}$. The experiments were performed in triplicate and the complete hemolysis (positive control) was determined by using $1 \%$ Triton $\mathrm{X}-100$. Hemolysis less than $10 \%$ point to a good hemocompatibility and non-toxicity of the molecules tested. ${ }^{72,73}$

$\mathrm{FeCl}_{3}$-induced arterial thrombosis model

$\mathrm{BALB} / \mathrm{c}$ mice were anesthetized subcutaneously with xylazin $\left(16 \mathrm{mg} \mathrm{kg}^{1}\right)$ and ketamine $\left(100 \mathrm{mg} \mathrm{kg}^{-1}\right)$. The right common carotid artery was isolated via a midline cervical incision, and the blood flow was monitored continuously using a Transonic Systems 0.5VB doppler flow probe coupled to a Transonic Systems TS420 flowmeter, as described previously. ${ }^{74}$ Thrombus formation was induced by applying a piece of filter paper $\left(1 \times 2 \mathrm{~mm}^{2}\right)$ saturated with a $7.5 \% \mathrm{FeCl}_{3}$ solution on the adventitial surface of the artery for $3 \mathrm{~min}$. Mean carotid artery blood flow was monitored for 60 min or until stable occlusion occurred (defined as a blood flow of $0 \mathrm{~mL} \mathrm{~min}^{-1}$ for $5 \mathrm{~min}$ ), at which time the experiment was terminated. All inhibitory compounds were diluted in a 5\% solution of gum arabic and administered through oral gavage $\left(10 \mathrm{mg} \mathrm{kg}^{-1}\right)$ to animals previously fastened for $1 \mathrm{~h}$. A solution of $1 \%$ DMSO was used as a negative control. All animal studies were performed in accordance with Institutional Animal Care and Use Committee (IACUC) (UFF-Comissão de Ética no Uso de Animais (CEUA)) under the protocol No. 486.

\section{Evaluation as pan assay interference compounds (PAINS)}

The compounds library was submitted to FAF-Drugs 3 to filter out problematic structures (i.e., covalent inhibitors and toxicophores), PAINS, isotopes, large compounds (> 120 heavy atoms) and select fragments using a physicochemical filter (molecular weight $\leq 350 \mathrm{Da}$; hydrogen bond donors $\leq 3$; hydrogen bond acceptors $\leq 8$; $\operatorname{clog} \mathrm{P} \leq 3$; heavy atoms $\leq 22$; and rotatable bonds $\leq 6$ ). All fragments were classified as "Accepted" due to no structural alerts and satisfying the physicochemical filter), In order to predict permeability and stability issues we used the "golden triangle" plot developed by Johnson et al. ${ }^{36}$ and available as an output of FAF-Drugs3 server.

\section{Statistical analysis}

All experimental results are the mean of three experiments performed in duplicate. Statistical analysis were carried out using one-way analysis of variance 
(ANOVA) $(p<0.05$ or $p<0.001)$ followed by Tukey's post-hoc test using SPSS 14.0 software. $^{75}$

\section{Redocking analysis}

To verify the efficiency of the docking methodology, the tridimensional structures of the inhibitors originally present in the crystallographic structure of both target proteins were removed and redocked into the target protein using the same methodology proposed for compounds to be screened. The efficiency of the methodology was obtained by comparing the docking pose from both inhibitors with their original pose obtained from the crystallographic structures.

\section{Supplementary Information}

Supplementary information (additional biochemical data and analytical chemical data (yield, melting point, FTIR, NMR, HRMS)) is available free of charge at http://jbcs.sbq.org.br as PDF file.

\section{Acknowledgments}

This work is a collaboration research project of members of the Rede Mineira de Química (RQ-MG) supported by FAPEMIG-Brazil (Project: CEX-RED-00010-14). We thank CAPES, CNPq, FAPERJ, and the Program for Technological Development in Tools for Health-RPTFiocruz for use of its facilities.

\section{References}

1. Ma, D.-L.; Chan, D. S.-H.; Leung, C.-H.; Chem. Soc. Rev. 2013, 42, 2130.

2. Duffy, B. C.; Zhu, L.; Decornez, H.; Kitchen, D. B.; Bioorg. Med. Chem. 2012, 20, 5324.

3. Artese, A.; Alcaro, S.; Moraca, F.; Reina, R.; Ventura, M.; Costantino, G.; Beccari, A. R.; Ortuso, F.; Future Med. Chem. 2013, 5, 907.

4. Bernardo, P. H.; Tong, J. C.; Methods Mol. Biol. 2012, 800, 25.

5. Gane, P. J.; Chan, A. W. E.; Methods Mol. Biol. 2013, 1008, 479.

6. Roy, A.; McDonald, P. R.; Sittampalam, S.; Chaguturu, R.; Curr. Pharm. Biotechnol. 2010, 11, 764.

7. Sheppard, D. W.; Lipkin, M. J.; Harris, C. J.; Catana, C.; Stouten, P. F.; Curr. Pharm. Des. 2013, 20, 3314.

8. Tian, S.; Sun, H.; Li, Y.; Pan, P.; Li, D.; Hou, T.; J. Chem. Inf. Model. 2013, 53, 2743.

9. Houston, D. R.; Walkinshaw, M. D.; J. Chem. Inf. Model. 2013, 53,384 .

10. Yu, W.; Xiao, H.; Lin, J.; Li, C.; J. Med. Chem. 2013, 56, 4402.
11. Joseph-McCarthy, D.; Campbell, A. J.; Kern, G.; Moustakas, D.; J. Chem. Inf. Model. 2014, 54, 693.

12. Harris, C. J.; Hill, R. D.; Sheppard, D. W.; Slater, M. J.; Stouten, P. F. W.; Comb. Chem. High Throughput Screening 2011, 14, 521.

13. Quinlan, D. J.; Eriksson, B. I.; Best Pract. Res., Clin. Haematol. 2013, 26, 171.

14. Keeling, D.; Cotter, F.; Br. J. Haematol. 2013, 160, 1.

15. Palladino, M.; Merli, G.; Thomson, L.; Expert Opin. Invest. Drugs 2013, 22, 1465.

16. Faria, J. V.; Vegi, P. F.; Miguita, A. G. C.; Santos, M. S.; Boechat, N.; Bernardino, A. M. R.; Bioorg. Med. Chem. 2017, 25, 5891.

17. Agrawal, R.; Jain, P.; Dikshit, S. N.; Curr. Drug Targets 2012 , 13,863 .

18. Agnelli, G.; Buller, H. R.; Cohen, A.; Curto, M.; Gallus, A. S.; Johnson, M.; Porcari, A.; Raskob, G. E.; Weitz, J. I.; N. Engl. J. Med. 2013, 368, 699.

19. Pappalardo, F.; Scandroglio, A. M.; Potapov, E.; Stepanenko, A.; Maj, G.; Krabatsch, T.; Zangrillo, A.; Koster, A.; Hetzer, R.; Minerva Anestesiol. 2012, 78, 330.

20. Favaloro, E. J.; Lillicrap, D.; Lazzari, M. A.; Cattaneo, M.; Mazurier, C.; Woods, A.; Meschengieser, S.; Blanco, A.; Kempfer, A. C.; Hubbard, A.; Chang, A.; Haemophilia 2004, 10, 164.

21. Coppens, M.; Eikelboom, J. W.; Gustafsson, D.; Weitz, J. I.; Hirsh, J.; Circ. Res. 2012, 111, 920.

22. Kumar, R.; Smith, R. E.; Henry, B. L.; J. Intensive Care Med. 2015, 30, 462 .

23. Gustafsson, D.; Bylund, R.; Antonsson, T.; Nilsson, I.; Nyström, J.-E.; Eriksson, U.; Bredberg, U.; Teger-Nilsson, A.-C.; Nat. Rev. Drug Discovery 2004, 3, 649.

24. Ferm, R. J.; Riebsomer, J. L.; Chem. Rev. 1954, 54, 593.

25. Wong, P. C.; Pinto, D. J. P.; Zhang, D.; J. Thromb. Thrombolysis 2011, 31, 478.

26. Lane, D. A.; Phillipou, H.; Huntington, J. A.; Blood 2005, 106, 2605.

27. Faria, J. V.; dos Santos, M. S.; Bernardino, A. M. R.; Becker, K. M.; Machado, G. M. C.; Rodrigues, R. F.; Canto-Cavalheiro, M. M.; Leon, L. L.; Bioorg. Med. Chem. Lett. 2013, 23, 6310.

28. dos Santos, M. S.; Oliveira, M. L. V.; Bernardino, A. M. R.; de Leo, R. M.; Amaral, V. F.; de Carvalho, F. T.; Leon, L. L.; CantoCavalheiro, M. M.; Bioorg. Med. Chem. Lett. 2011, 21, 7451.

29. James, R. C.; Pierce, J. G.; Okano, A.; Xie, J.; Boger, D. L.; ACS Chem. Biol. 2012, 7, 797.

30. Li, J.; Bénard, S.; Neuville, L.; Zhu, J.; Org. Lett. 2012, 14, 5980.

31. ChemAxon; Marvin 16.1.4.0; ChemAxon, Budapest, Hungary, 2016. Available at https://chemaxon.com/products/marvin, accessed in July 2018.

32. Réeff, J.; Gaignaux, A.; Goole, J.; De Vriese, C.; Amighi, K.; Drug Dev. Ind. Pharm. 2013, 39, 1731. 
33. Bobko, A. A.; Ivanov, A.; Khramtsov, V. V.; Free Radical Res. 2012, 47, 74.

34. Campbell, N. H.; Evans, D. A.; Lee, M. P. H.; Parkinson, G. N.; Neidle, S.; Bioorg. Med. Chem. Lett. 2006, 16, 15.

35. Lagorce, D.; Sperandio, O.; Baell, J. B.; Miteva, M. A.; Villoutreix, B. O.; Nucleic Acids Res. 2015, 43, W200. FAF-Drugs 3 software is available at http://fafdrugs3.mti.univparis-diderot.fr/, accessed in July 2018.

36. Johnson, T. W.; Dress, K. R.; Edwards, M.; Bioorg. Med. Chem. Lett. 2009, 19, 5560.

37. Wavefunction, Inc.; Spartan'10 for Windows; Wavefunction, Inc., Irvine, USA, 2010.

38. Gallwitz, M.; Enoksson, M.; Thorpe, M.; Hellman, L.; PLoS One 2012, 7, e31756.

39. Jiao, D.; Golubkov, D.; Darden, T. A.; Ren, P.; Proc. Natl. Acad. Sci. U. S. A. 2008, 105, 6290.

40. Andrews, J. M.; Roman, D. P.; Bing, D. H.; J. Med. Chem. 1978, $21,1202$.

41. Fradera, X.; Kasemier, B.; Carswell, E.; Cooke, A.; Oubrie, A.; Hamilton, W.; Dempster, M.; Krapp, S.; Nagel, S.; Jestel, A.; Acta Crystallogr., Sect. F: Struct. Biol. Cryst. Commun. 2012, 68, 404.

42. Cho, J. E.; Kim, J. T.; Jung, S. H.; Kang, N. S.; Bull. Korean Chem. Soc. 2013, 34, 1212.

43. Huggins, D. J.; Sherman, W.; Tidor, B.; J. Med. Chem. 2012, 55,1424

44. Candia, M.; Lopopolo, G.; Altomare, C.; Expert Opin. Ther. Pat. 2009, 19, 1535.

45. Morris, G. M.; Huey, R.; Lindstrom, W.; Sanner, M. F.; Belew, R. K.; Goodsell, D. S.; Olson, A. J.; J. Comput. Chem. 2009, 16,2785

46. Lounnas, V.; Ritschel, T.; Kelder, J.; McGuire, R.; Bywater, R. P.; Foloppe, N.; Comput. Struct. Biotechnol. J. 2013, 5, 1.

47. Ferreira, L. G.; dos Santos, R. N.; Oliva, G.; Andricopulo, A. D.; Molecules 2015, 20, 13384.

48. Sliwoski, G.; Kothiwale, S.; Meiler, J.; Lowe, E. W.; Pharmacol. Rev. 2014, 66, 334.

49. Moura, L. A.; de Almeida, A. C. M.; Domingos, T. F. S.; OrtizRamirez, F.; Cavalcanti, D. N.; Teixeira, V. L.; Fuly, A. L.; Mar. Drugs 2014, 12, 2471. Available at https://www.organicchemistry.org/prog/peo/, accessed in July 2018.

50. Almasirad, A.; Mousavi, Z.; Tajik, M.; Assarzadeh, M. J.; Shafiee, A.; J. Pharm. Sci. 2014, 22, 1.

51. Khan, G. A.; Lindberg, R.; Grabic, R.; Fick, J.; J. Pharm. Biomed. Anal. 2012, 66, 24.

52. Kumar, D.; Mariappan, G.; Husain, A.; Monga, J.; Kumar, S.; Arabian J. Chem. 2014, 10, 344.

53. Piotrowski, R.; Kryński, T.; Baran, J.; Futyma, P.; Stec, S.; Kułakowski, P.; Cardiol. J. 2014, 21, 299.

54. Zhang, B.; Lin, S.; Biomed. Environ. Sci. 2009, 22, 40

55. Hawes, E. M.; Deal, A. M.; Funk-Adcock, D.; Gosselin, R.; Jeanneret, C.; Cook, A. M.; Taylor, J. M.; Whinna, H. C.;
Winkler, A. M.; Moll, S.; J. Thromb. Haemostasis 2013, 11, 1493

56. Kazmi, R. S.; Lwaleed, B. A.; Br. J. Clin. Pharmacol. 2011, 72, 593.

57. Vandiver, J. W.; Vondracek, T. G.; Pharmacotherapy 2012, 32, 546.

58. Baglin, T.; Int. J. Lab. Hematol. 2011, 33, 333.

59. Dager, W. E.; Gosselin, R. C.; Kitchen, S.; Dwyre, D.; Ann. Pharmacother. 2012, 46, 1627.

60. Fawole, A.; Daw, H. A.; Crowther, M. A.; Cleve. Clin. J. Med. 2013, 80, 443 .

61. Lacroix, I. M. E.; Li-Chan, E. C. Y.; Int. J. Mol. Sci. 2014, 15, 20846.

62. Kleszczynska, H.; Bonarska, D.; Oswiecimska, M.; Sarapuk, J.; Pol. J. Environ. Stud. 2003, 12, 63.

63. Hann, M. M.; Oprea, T. I.; Curr. Opin. Chem. Biol. 2004, 8 , 255.

64. Liao, C.; Park, J.-E.; Bang, J. K.; Nicklaus, M. C.; Lee, K. S.; ACS Med. Chem. Lett. 2010, 1, 110; ChemAxon; Instant JChem 16.1.4.0; ChemAxon, Budapest, Hungary, 2016. Available at https://chemaxon.com/products/instant-jchem, accessed in July 2018.

65. Huang, C. C.; Meng, E. C.; Morris, J. H.; Pettersen, E. F.; Ferrin, T. E.; Nucleic Acids Res. 2014, 42, W478.

66. DMS; UCSF Computer Graphics Laboratory, San Francisco, CA, 2003. Available at http://www.cgl.ucsf.edu/Overview/ software.html, accessed in August 2018.

67. Allen, W. J.; Balius, T. E.; Mukherjee, S.; Brozell, S. R.; Moustakas, D. T.; Lang, P. T.; Case, D. A.; Kuntz, I. D.; Rizzo, R. C.; J. Comput. Chem. 2015, 36, 1132.

68. Kastenholz, M. A.; Pastor, M.; Cruciani, G.; Haaksma, E. E.; Fox, T.; J. Med. Chem. 2000, 43, 3033.

69. Sathler, P. C.; Lourenço, A. L.; Rodrigues, C. R.; da Silva, L. C. R. P.; Cabral, L. M.; Jordão, A. K.; Cunha, A. C.; Vieira, M. C. B.; Ferreira, V. F.; Carvalho-Pinto, C. E.; Kang, H. C.; Castro, H. C.; Thromb. Res. 2014, 134, 376.

70. MathWorks; MATLAB version 9.1; MathWorks, Natick, USA, 2016.

71. GraphPad Software; GraphPad Prism, version 6; GraphPad Software, San Diego, USA, 2014.

72. Bauer, M.; Lautenschlaeger, C.; Kempe, K.; Tauhardt, L.; Schubert, U. S.; Fischer, D.; Macromol. Biosci. 2012, 12, 986.

73. Fischer, D.; Li, Y.; Ahlemeyer, B.; Krieglstein, J.; Kissel, T.; Biomaterials 2003, 24, 1121 .

74. Ma, D.; Mizurini, D. M.; Assumpção, T. C.; Li, Y.; Qi, Y.; Kotsyfakis, M.; Ribeiro, J. M.; Monteiro, R. Q.; Francischetti, I. M.; Blood 2013, 122, 4094.

75. SPSS for Windows 14; SPSS Inc., Chicago, IL, USA, 2005.

Submitted: May 2, 2018

Published online: August 9, 2018 